\title{
Gene expression profile during proliferation and differentiation of rainbow trout adipocyte precursor cells
}

\author{
Marta Bou ${ }^{1,3}$, Jerôme Montfort ${ }^{2}$, Aurélie Le Cam², Cécile Rallière ${ }^{2}$, Véronique Lebret ${ }^{2}$, Jean-Charles Gabillard ${ }^{2}$, \\ Claudine Weil' ${ }^{2}$ Joaquim Gutiérrez ${ }^{1}$, Pierre-Yves Rescan ${ }^{2}$, Encarnación Capilla ${ }^{1}$ and Isabel Navarro ${ }^{1 *}$
}

\begin{abstract}
Background: Excessive accumulation of adipose tissue in cultured fish is an outstanding problem in aquaculture. To understand the development of adiposity, it is crucial to identify the genes which expression is associated with adipogenic differentiation. Therefore, the transcriptomic profile at different time points (days 3, 8, 15 and 21) along primary culture development of rainbow trout preadipocytes has been investigated using an Agilent trout oligo microarray.

Results: Our analysis identified 4026 genes differentially expressed (fold-change $>3$ ) that were divided into two major clusters corresponding to the main phases observed during the preadipocyte culture: proliferation and differentiation. Proliferation cluster comprised 1028 genes up-regulated from days 3 to 8 of culture meanwhile the differentiation cluster was characterized by 2140 induced genes from days 15 to 21 . Proliferation was characterized by enrichment in genes involved in basic cellular and metabolic processes (transcription, ribosome biogenesis, translation and protein folding), cellular remodelling and autophagy. In addition, the implication of the eicosanoid signalling pathway was highlighted during this phase. On the other hand, the terminal differentiation phase was enriched with genes involved in energy production, lipid and carbohydrate metabolism. Moreover, during this phase an enrichment in genes involved in the formation of the lipid droplets was evidenced as well as the activation of the thyroid-receptor/retinoic $X$ receptor (TR/RXR) and the peroxisome proliferator activated receptors (PPARs) signalling pathways. The whole adipogenic process was driven by a coordinated activation of transcription factors and epigenetic modulators.
\end{abstract}

Conclusions: Overall, our study demonstrates the coordinated expression of functionally related genes during proliferation and differentiation of rainbow trout adipocyte cells. Furthermore, the information generated will allow future investigations of specific genes involved in particular stages of fish adipogenesis.

Keywords: Adipogenesis, Teleost fish, Adipose tissue, Microarray, Transcriptome

\section{Background}

The ongoing intensification of salmonids aquaculture industry has led to the development of diets with high lipid content, which can induce an increase in subcutaneous, intramuscular and especially in visceral fat depots [1]. This excessive adiposity may entail a negative impact on the sector, reducing the efficiency of the production.

\footnotetext{
* Correspondence: mnavarro@ub.edu

'Department of Cell Biology, Physiology and Immunology, Faculty of Biology, University of Barcelona, Av. Diagonal 643, 08028 Barcelona, Spain

Full list of author information is available at the end of the article
}

Mature adipocytes are known to play an important role controlling energy balance in mammals by storing fatty acids in the form of triglycerides in periods of excess of energy and by releasing fatty acids when are needed. Despite of the relevance of this issue, very little is known about the factors regulating the development of adipose tissue in fish, and the possible health alterations associated to an increased fat deposition. While excess of adipose tissue in humans, which occurs in obesity, is known to contribute to the development of many aspects of the pathology of metabolic syndrome and other diseases $[2,3]$, 
the metabolic consequences of a high adiposity are still not well known in fish.

In order to understand the development of adiposity, it is crucial to identify the factors and mechanisms that regulate the recruitment of mesenchymal stem cells (MSCs) of the vascular stromal fraction of the adipose tissue and its transformation into lipid-filled adipocytes. Adipogenesis has been described as a two-step developmental process consisting on the commitment of undifferentiated MSCs into preadipocytes and the further development of these cells into fully functional mature adipocytes [4]. In fish, like in mammals, adipogenesis takes place as a consequence of normal cell turnover and is due to the need of storing energy $[5,6]$. Therefore, growth of adipose tissue includes the hypertrophy of already existing adipocytes and the proliferation and differentiation of new ones from MSCs.

Adipogenesis has been extensively studied in mammals [7] and several cell and animal models have been successfully used to describe the chronology of the molecular events governing this process. Many are the studies highlighting the importance of the interplay of both, activating and inhibiting signals and thus involving proadipogenic and anti-adipogenic factors [7-10]. We have previously shown that fish primary preadipocytes differentiate into mature adipocytes in vitro and that these cells represent a very helpful model system to study adipose tissue development in fish [5, 6]. Some of the well-known key adipogenic transcription factors described in mammals, such as peroxisome proliferator activated receptor $\gamma$ (PPAR $\gamma)$ and CCAAT-enhancer binding protein $\alpha(\mathrm{C} / \mathrm{EBP} \alpha)$, have been identified and linked to an adipogenic function in fish as well $[5,11,12]$.

Insulin favors differentiation into mature adipocytes in rainbow trout, gilthead sea bream and other fish species of cultured preadipocytes $[5,6,13]$. However, a common trait in fish is that lipids, especially high concentrations of fatty acids, play an essential role in adipocyte differentiation $[5,6,11,13]$. However, only one study has extensively analyzed the gene expression profile during adipogenesis in Atlantic salmon [14].

Apart from controlling energy storage and mobilization, adipose tissue has an important function as a major endocrine organ secreting diverse adipokines and regulating therefore many physiological aspects $[15,16]$. For instance, the cytokine tumor necrosis factor $\alpha$ (TNF $\alpha)$ is expressed in fish adipose tissue and is well known by its anti-adiposity actions $[5,17,18]$. Leptin and adiponectin are known to be the most abundant proteins secreted by mammalian adipocytes [19], contrary to what has been described so far in teleost species, where leptin is primarily expressed in the liver [20] and adiponectin in muscle [21-23]. These specific features highlight the need to further investigate the physiological and secretory functions of fish adipose tissue.
Here, to characterize the genetic basis of adipogenesis in rainbow trout, a genome-wide expression profiling combined with quantitative PCR (qPCR) and Western blot analysis was performed at 4 different time-points along the adipocyte primary culture. The main goal of this study was to provide deeper insights into the dynamics of adipocyte conversion by defining the cascades of gene expression as well as to identify possible novel adipogenic mediators and markers in this fish species. Likewise, we aimed to unravel yet undiscovered mechanisms and provide a basis for the identification of proteins that could serve in the future as potential links between the adipocyte and the process of whole body energy homeostasis.

\section{Methods}

\section{Animals}

Rainbow trout (Oncorhynchus mykiss Walbaum 1792) weighting from 200 to $250 \mathrm{~g}$ were obtained from the "Truites del Segre" fish farm (Lleida, Spain). Fish were acclimatized to a $12 \mathrm{~h}$ light: $12 \mathrm{~h}$ dark photoperiod and $14 \pm 1{ }^{\circ} \mathrm{C}$ in a closed circuit flow system located in the Faculty of Biology at the University of Barcelona for 2 weeks prior to the commencement of the experiment. Fish were fed daily ad libitum on a commercial diet based on fishmeal and fish oil (Dibaq Diproteg, Segovia, Spain).

\section{Primary culture of preadipocyte cells}

All reagents were purchased from Sigma-Aldrich (Tres Cantos, Spain) and all tissue culture plastic ware was obtained from NUNC (Labclinics, Barcelona, Spain) unless stated otherwise.

Fish were fasted $24 \mathrm{~h}$ before the experiments. The animals were killed by a blow to the head under anesthesia (3-aminobenzoic acid ethyl ester, MS-222; $100 \mu \mathrm{g} / \mathrm{ml}$ ), which was followed by immersion in $70 \%$ ethanol for $30 \mathrm{~s}$ to sterilize the external surfaces. Cells for each experiment were isolated from a pool of white adipose tissue of 6-7 fish and cultured as described elsewhere [5]. The use of pooled tissue minimizes fish-specific variation in the experimental measurements. A total of four independent cultures $(n=4)$ were performed, each of which derived from cells isolated from a different pool of white adipose tissue of 6-7 fish (i.e. 24-28 fish in total). Briefly, the dissected visceral fat tissue was washed with Krebs-HEPES buffer ( $\mathrm{pH} 7.4$ ) and was digested for $1 \mathrm{~h}$ with type II collagenase $130 \mathrm{UI} / \mathrm{mL}$ containing $1 \%$ bovine serum albumin in Krebs-HEPES buffer at $18{ }^{\circ} \mathrm{C}$. The resulting cell suspension was filtered $(100 \mu \mathrm{m})$ and centrifuged at $700 \mathrm{~g}$ for $10 \mathrm{~min}$ and the pellet was treated with erythrocyte lysing buffer $\left(0.154 \mathrm{M} \mathrm{NH}_{4} \mathrm{Cl}\right.$, $10 \mathrm{mM} \mathrm{KHCO}$, and $0.1 \mathrm{mM}$ EDTA) for $5 \mathrm{~min}$ at room temperature. After washing, the cells were centrifuged again at $700 \mathrm{~g}$ for $10 \mathrm{~min}$. The cell pellet was resuspended 
in growth medium, consisting on Leibovitz's L-15 medium containing 10\% fetal bovine serum, $2 \mathrm{mM} \mathrm{L}$-glutamine and $1 \%$ antibiotic/antimycotic solution. Cells were counted, diluted, seeded in pretreated flasks or six-well plates $\left(25 \mathrm{~cm}^{2}\right.$ or $9.6 \mathrm{~cm}^{2} /$ well respectively), with $1 \%$ gelatin at a density of $2 \cdot 10^{4}$ cells $/ \mathrm{cm}^{2}$ and kept at $18{ }^{\circ} \mathrm{C}$. For each experimental condition either one flask (RNA extraction) or two wells pooled together (Western blot) were used. After confluence (day 8 ), cells were induced to differentiate by means of a growth medium supplemented with $10 \mu \mathrm{g} / \mathrm{mL}$ insulin, $0.5 \mathrm{mM}$ 3-isobutyl-1-methylxanthine (IBMX), $0.25 \mu \mathrm{M}$ dexamethasone and $10 \mu \mathrm{L} / \mathrm{mL}$ lipid mixture. Media were changed every 2 days during the whole procedure. Samples were collected at day 3 (mesenchymal stem cells), day 8 (proliferated cells), day 15 (committed preadipocytes) and day 21 (mature adipocytes). The cells were daily assessed under light microscopy to check the morphology and ensure that they followed the already described developmental process $[5,11,14,24]$.

\section{RNA extraction and CDNA synthesis}

Total RNA from adipocyte cells was extracted using the TriReagent method (Ambion, Alcobendas, Spain) following the manufacturer's recommendations. The quantity of isolated RNA was determined by spectrophotometry with a ND-2000 NanoDrop (Thermo Fisher Scientific, Alcobendas, Spain) and the quality was assessed using a Bionalyzer (Agilent). The total RNA was used for microarray and qPCR analysis.

For cDNA synthesis $5 \mu \mathrm{g}$ of total RNA was reversetranscribed using High Capacity cDNA Reverse Transcription Kit (Applied Biosystems) in a $25 \mu \mathrm{l}$ reaction volume according to the instructions provided by the manufacturer. The reverse-transcription products (cDNA) were diluted by the addition of nuclease-free water to a final volume of $200 \mu \mathrm{l}$. Reverse transcription was performed in duplicate for each individual sample.

\section{Quantitative real-time PCR (qPCR) analysis}

qPCR measurements were performed in a StepOnePlus Tm system (Applied Biosystems) as described in C Weil, V Lebret and JC Gabillard [25]. Briefly, $5 \mu$ of diluted cDNA was amplified in duplicates containing Fast SYBR Green Master Mix (Applied Biosystems) and specific primers at a final concentration of $600 \mathrm{nM}$. The qPCR primer sequences for the target genes and the reference gene are shown in Table 1. Primers were designed to span exon-boundaries if possible (Genamics Expression software) using known sequences from the rainbow trout nucleotide databases (INRA-Sigenae) and previously published $[25,26]$.

Relative quantity of each gene was determined from a standard curve consisting of serial dilutions of a pool of cDNAs obtained from isolated mature adipocytes and expressed as Arbitrary Units (A.U.). This calculation was performed using the software included in the StepOne plus Tm System which corrects for differences in amplification efficiencies. Primer efficiencies ranged from 90 to $103 \%$. Specificity of the amplification reaction was verified by analysis of melting curves. $18 \mathrm{~S}$ was used for the normalization of qPCR data since its RNA abundance was stable along the cell culture $(p>0.05)$. The two cDNAs obtained from each sample were run in a single plate for each gene assay together with negative controls (reverse transcriptase-free samples and RNA-free samples).

\section{Microarray analysis}

The adipocyte transcriptome was analyzed using an Agilent-based microarray platform with $8 \times 60 \mathrm{~K}$ probes per slide previously described [27] and registered in GEO with the platform record GPL15840. Microarray data sets have been submitted to the GEO-NCBI with the accession number GSE90058. Total RNA from cells at different developmental stages (days 3, 8, 15 and 21) from four independent cultures, each of which derived from cells isolated from a different pool of white adipose tissue of 6-7 fish, was labelled with $\mathrm{Cy} 3$ according to the manufacturer's instructions (Agilent). Briefly, RNA was first reverse transcribed, using a polyDTT7 primer, Cy3 was incorporated by a T7 polymerase mediated transcription and excess dye was removed using an RNeasy kit (Quiagen). The level of dye incorporation was evaluated using a spectrophotometer (Nanodrop ND1000, LabTech). Labelled RNA was then fragmented in the appropriate buffer (Agilent) for $30 \mathrm{~min}$ at $60{ }^{\circ} \mathrm{C}$ before dilution $(\mathrm{v} / \mathrm{v})$ in hybridization buffer. Hybridizations were performed in a microarray hybridization oven (Agilent) overnight at $65^{\circ} \mathrm{C}$, using two high-density oligonucleotide microarray slides. Following hybridization, the slides were rinsed in gene expression wash buffers 1 and 2 (Agilent) and scanned at a $3 \mu \mathrm{m}$ resolution using an Agilent G2505 microscanner. Fluorescence intensity was calculated using the standard procedures contained in the Agilent Feature Extraction software version 10.7 and the data were normalized using GeneSpring software. An ANOVA $(p<0.02)$ and an average fold change of $>3$ were used as the criteria for defining genes as differentially expressed between the different days along the cell culture. For clustering analysis, data were log transformed, median-centered and an average linkage clustering was carried out using CLUSTER software. The results were visualized using TREEVIEW [28]. Biological functions and pathways were generated and analyzed using Ingenuity Pathway Analysis software (IPA, Ingenuity Systems, CA).

\section{Western blot analysis}

Protein extraction and Western blot analysis were performed as previously reported [29]. Twenty $\mu \mathrm{g}$ of protein were subjected to SDS-PAGE gel electrophoresis and 
Table 1 Rainbow trout primer sequences used for qPCR

\begin{tabular}{|c|c|c|c|}
\hline Gene & Accession number & Primer sequence $\left(5^{\prime}-3^{\prime}\right)$ & Annealing $\mathrm{T}\left({ }^{\circ} \mathrm{C}\right)$ \\
\hline \multirow[t]{2}{*}{ ACSL1 } & CR363150.p.om.8 & F: TGCAATCTAGCAAGGTTCCTTTTG & 60 \\
\hline & & R: TCCAAGCAGAAACCCAGTACAGAA & \\
\hline \multirow[t]{2}{*}{ GPDH } & AF027130.p.om.8 & F: ATGACCACAGTCCACGCCTACAC & 60 \\
\hline & & R: GGCAGGTTAGGTCCACCACTGA & \\
\hline \multirow[t]{2}{*}{ IGFBP5 } & DQ206713 & F: ACTTCACGCGCTTCTCCATGGCA & 60 \\
\hline & & R: CGAGACTCATGATCTATGGGTGGA & \\
\hline \multirow[t]{2}{*}{ IGFBP7 } & DQ146965 & F: GCTCCGATGGAGTGACCTATA & 60 \\
\hline & & R: ACAATGACAGGTGCTGTTGCG & \\
\hline \multirow[t]{2}{*}{ PCNA } & CA358086.s.om.10 & F: ATACGGGCAAACTCTCCTGATGGC & 60 \\
\hline & & R: CAACGCAGACACACTCGCCCTT & \\
\hline \multirow[t]{2}{*}{ CPEPCK } & {$[26]$} & F: CCCAGTGCCTGTGGGAAAAC & 60 \\
\hline & & R: CCACACCGAAAAAGCCGTTC & \\
\hline \multirow[t]{2}{*}{ PLIN2 } & CB494091.p.om.8 & F: GATGGCAATGAGGCAGAGAACA & 60 \\
\hline & & R: AGGCAGAGTGGCTAAGGGACAG & \\
\hline \multirow[t]{2}{*}{$18 \mathrm{~S}$} & AF308535 & F: CGGAGGTTCGAAGACGATCA & 60 \\
\hline & & R: TCGCTAGTTGGCATCGTTTAT & \\
\hline
\end{tabular}

$\mathrm{F}$, forward; $\mathrm{R}$, rever se; $\mathrm{T}$, temperature

Western blot analysis was performed using the appropriate antibodies for long-chain acyl-CoA synthetase (ACSL-1) (cat no 98925), proliferating cell nuclear antigen (PCNA) (cat no 7907), phosphoenolpyruvate carboxykinase (PEPCK) (cat no 32879), perilipin 2 (PLIN2) (cat no 32888), all from Cell Signaling Technology Inc (Beverly, MA) and PPAR (PPARy; cat no 7196; Santa Cruz Biotechnology). Immunoreactive bands were visualized using an enhanced chemiluminescence kit (Pierce ECL Western Blotting Substrate; Thermo Scientific, Alcobendas, Spain) and quantified by densitometric scanning using ImageJ software (National Institutes of Health, Bethesda, MD, USA). Some of these antibodies have been previously shown to successfully cross-react with fish, such as PPARy [5] and PCNA [30]. For those antibodies not tested previously, homogenates of rat liver were also run as a control in a contiguous lane to confirm the specificity of immunodetection (i.e. apparent molecular weight of the band). Western blots results were obtained from four independent cultures, each of which derived from cells isolated from a different pool of white adipose tissue of 6-7 fish.

\section{Results and discussion}

\section{Gene expression profile during adipogenesis}

In order to characterize the process of adipogenesis in rainbow trout, four independent primary cultures of adipocytes were performed and samples were collected at days 3, 8, 15 and 21 post seeding and used for microarray experiments. After bioinformatics analysis a total of 4026 genes were found differentially expressed ( $>3.0$-fold, $p<0.02$ ). Hierarchical clustering analysis of these differentially expressed genes was performed and two major clusters were identified (Fig. 1) and related to the main phases described during preadipocyte culture; proliferation (cluster 1) and differentiation (cluster 2). Proliferation cluster comprised 1028 genes that were upregulated from days 3 to 8 of culture meanwhile the cluster characterizing the differentiation phase included 2140 upregulated genes from days 15 to 21 of culture.

\section{Functional annotation of genes found in cluster 1 (Proliferation) and 2 (Differentiation)}

Cluster 1 comprised genes that were up-regulated during days 3 and/or 8 of culture. Significant biological functions associated with the proliferative phase of adipogenesis were determined by using Ingenuity pathway analysis (IPA) software (Additional files 1 and 2). The early stages of adipocyte development were characterized by a large number of genes involved in basic cellular and metabolic processes such as transcription, ribosome biogenesis, translation and protein folding. During this part of the culture the category of "Cellular Growth and Proliferation" was highly represented, with 254 molecules included in the functional annotation of "proliferation of cells" $\left(P=2 \cdot 10 \mathrm{E}^{-16}\right)$. Among the other significant categories present in the early stages of adipocyte development, the category "Tissue Morphology" that included the functional annotations of "quantity of cells" $\left(P=1.41 \mathrm{E}^{-17}\right)$ and "morphology of connective tissue" $\left(P=1.02 \mathrm{E}^{-6}\right)$ and the category of "Immune Cell Trafficking" $\left(P=5.43 \mathrm{E}^{-14}-3.07 \mathrm{E}^{-04}\right)$ and "Inflammatory Response" $\left(P=1.40 \mathrm{E}^{-12}-3.16 \mathrm{E}^{-04}\right)$ were also found. On the other hand, the "Eicosanoid Signaling" $\left(P=1.5 \mathrm{E}^{-04}\right)$ 


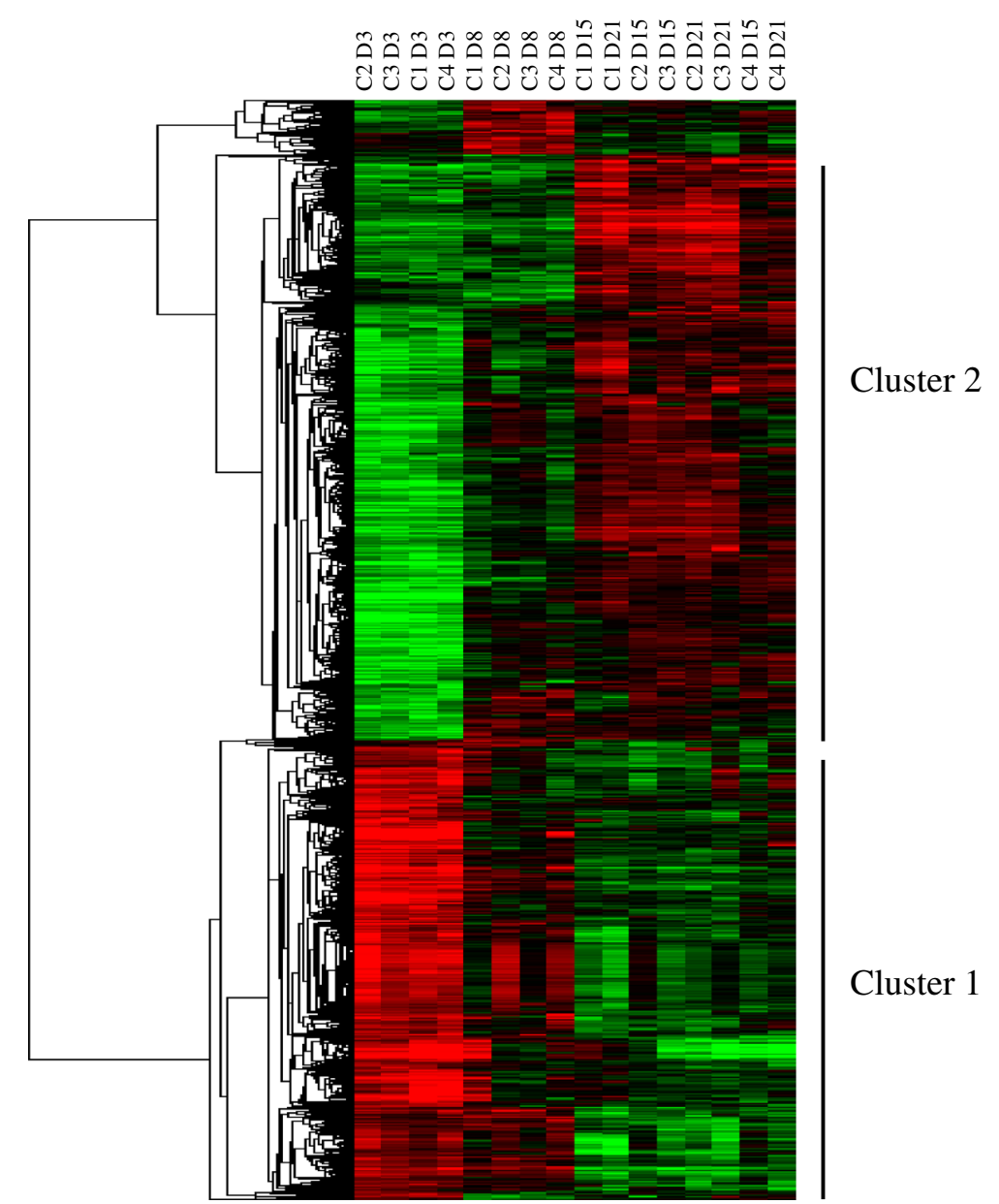

Fig. 1 Heat map of the hierarchical clustering of genes differentially expressed ( $>3.0$-fold, $p<0.02$ ) among different days along rainbow trout adipocyte culture. The horizontal dendrogram represents the correlation distances between gene expression levels. Every column represents one independent culture (C) at one time-point (D3, D8, D15; D21; days 3, 8, 15, 21 respectively) meanwhile the different genes are represented by individual rows. The red color indicates high levels of expression while green represents low levels of expression. The intensity of both colors is related to the transcript expression level. Data are presented in the same format in Figures 2-8

and the "Interleukin 8 (IL-8) Signaling" $\left(P=4.73 \mathrm{E}^{-04}\right)$ pathways were found within the top canonical pathways.

On the other hand, cluster 2 consisted on upregulated genes during days 15 and/or 21 of culture. During this second phase a remarkable number of genes involved in energy production, glucose and lipid metabolism were revealed by IPA analyses (Additional files 3 and 4). IPA analysis highlighted as top categories "Molecular and Cellular Functions" and "Molecular Transport", which included the functional annotations "transport of molecules" $\left(P=8.05 \mathrm{E}^{-11}\right)$, "concentration of lipid" $\left(P=1.82 \mathrm{E}^{-9}\right)$ and "transport of lipid" $\left(P=4.22 \mathrm{E}^{-7}\right)$ among others. Other top category represented was "Carbohydrate Metabolism", comprising 128 molecules and including functional annotations such as "glycolysis of cells" $\left(P=1.33 \mathrm{E}^{-10}\right)$, "metabolism of carbohydrate" $\left(P=3.97 \mathrm{E}^{-9}\right)$ and "gluconeogenesis" $\left(P=8.80 \mathrm{E}^{-5}\right)$. The category of "Cellular Growth and Proliferation" was also highly represented, with 250 molecules included in the functional annotations of "proliferation of cells" $\left(P=1.28 \mathrm{E}^{-11}\right)$ and "proliferation of connective tissue cells" $\left(P=3.35 \mathrm{E}^{-8}\right)$. "IL-8 signaling" $\left(P=2.58 \mathrm{E}^{-5}\right)$ was present again as one of the top canonical pathways, together with "TR/RXR Activation" $\left(P=1.15 \mathrm{E}^{-7}\right)$. Finally, the implication of the PPAR signaling pathway during this phase of the culture was also revealed $\left(P=1.37 \mathrm{E}^{-7}\right)$.

In order to describe and highlight the different processes that take place during culture development, including the proliferation and differentiation phases, the following results and corresponding discussion will be divided into different sections according to some selected functional groups of molecules. The first section will cover the main processes present during the early stages of adipocyte commitment and development. Next, the coordinated cascade of transcription factors that orchestrate fat cell progression will be presented, followed by the description of the main epigenetic factors identified. Subsequently, the relevance of 
two regulatory systems, the insulin and insulin-like growth factors (IGFs) and the eicosanoid signaling, will be discussed. Finally, a section concerning the main terminal regulators of adipocyte maturation present in our model system will be provided.

\section{Cell commitment and remodelling}

Initial phases of adipogenesis are characterized by the presence of pluripotent precursors (i.e. MSCs) of adipocytes. Many genes involved in cell fate (Fig. 2a) were differentially induced in the early steps of our cell culture. For instance, the presence of Notch1, which is a protein responsible for cell fate decision and implicated in the regulation of adipogenesis in 3T3-L1 cells [31], was revealed during the proliferative phase of the culture. During this phase we found overexpressed also the ribosomal protein S6 kinase delta-1 (Rps6kc1 or S6K1). S6K1 is involved in the commitment of embryonic stem cells to early

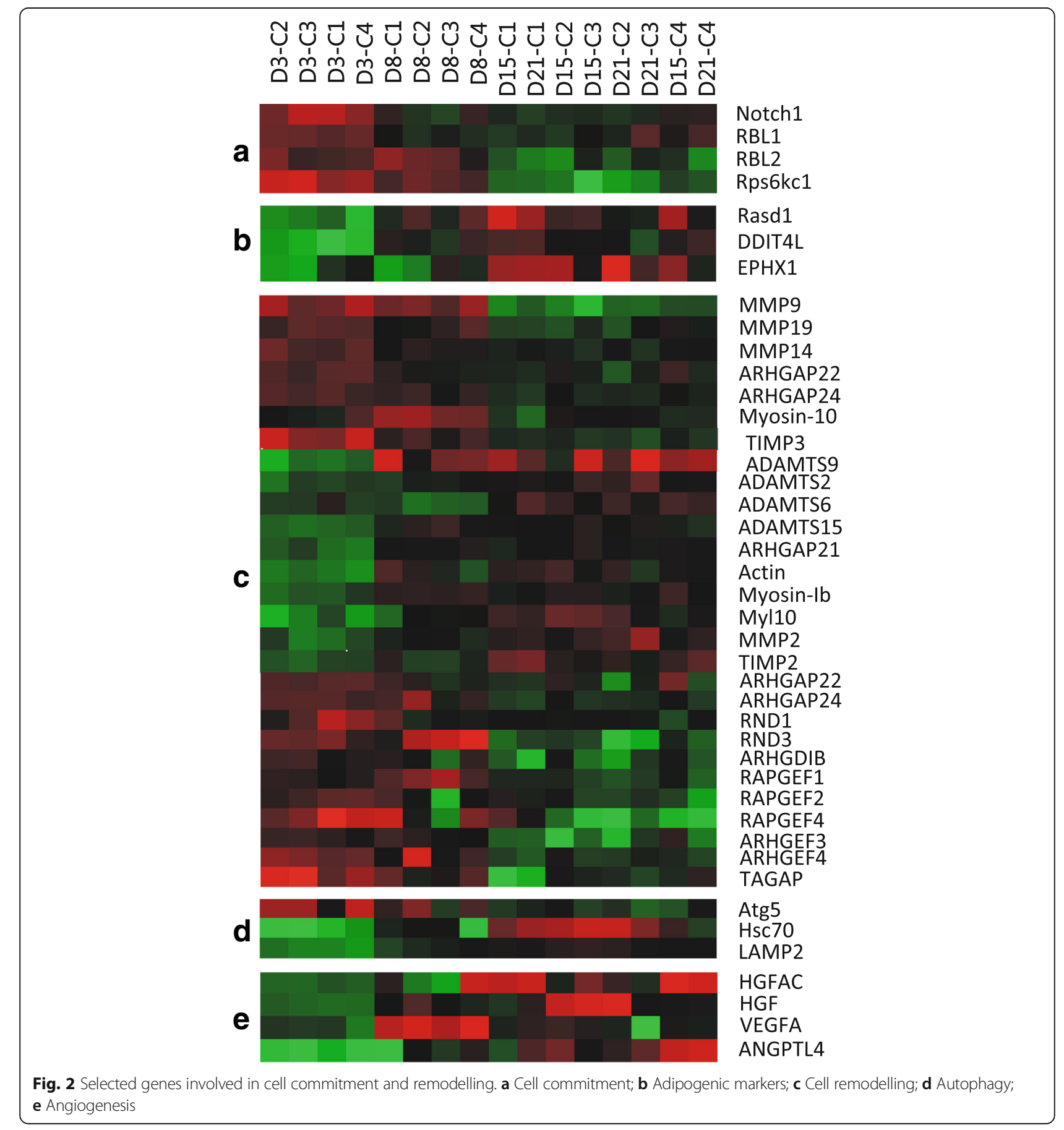


adipocyte progenitors in mice [32] and, is known to promote protein synthesis, cell growth and cell proliferation; processes that are of utmost importance during the early stages of the culture. On the other hand, the expression of the retinoblastoma-like proteins 1 (RBL1/p107) and 2 (RBL2/p130), which control cell cycle progression, was also evident during the first stages of cell development. RBL1 has been reported to be a crucial regulator for determining the adipocyte fate choices of stem cells committing to the white lineage, whereas its suppression is required for commitment to the brown-type fate [33]. In addition, alterations in the expression of both, RBL1 and RBL2 inhibit adipocyte differentiation [7]. In this sense, their expression in early stages and their down-regulation during days 15 and 21 of our culture will support this observation suggesting a role for these molecules in adipocyte commitment also in rainbow trout.

Some of the adipogenic markers described in human bone marrow-derived MSCs differentiating into the adipogenic lineage were present in our transcriptome study. Such is the case of dexamethasone-induced Ras-related protein 1 (RASD1), DNA damage-inducible transcript 4like protein (DDIT4L) and epoxide hydrolase 1 (EPHX1), which are highly expressed during adipocyte development with a peak at day 15 of culture (Fig. 2b) [34].

The dramatic alteration in cell shape, from a fibroblast to a spherical shape represents one of the first hallmarks of adipogenesis. Our analysis has shown the regulation of a large number of genes involved in this type of processes (Fig. 2c). For instance, we found a remarkable presence of members of the matrix metalloproteinases (MMPs) family, as well as transcripts encoding their tissue inhibitors (TIMPs), which are known to regulate MMP activity all along the culture [35]. MMP9 was upregulated during the proliferative phase while MMP2 was increased during differentiation. In freshly isolated mature adipocytes from humans both transcripts are present, and in agreement with our data, the expression of MMP2 was higher than that of MMP9. Moreover, in the same line, the expression analysis of MMPs during 3T3-F442A preadipocyte differentiation revealed that MMP2 showed a 13-fold increase in mRNA levels after 9 days of differentiation compared with non-differentiated cells, while MMP9 followed only a moderate increase during differentiation, reaching a maximal level after 7 days, and decreasing afterwards [36]. Accordingly, in the same study the inhibition of MMP2 and MMP9 markedly decreased adipocyte differentiation, highlighting their role during the development of these cells [36]. Furthermore, we also found MMP14 up-regulated during proliferation. The loss of this protein impairs adipogenesis in vivo in mice [37]. The relevance of the proteolytic activity during rainbow trout adipogenesis was also evidenced by the presence of many transcripts encoding various members of the ADAMTS (a disintegrin and metalloproteinase domain, with thrombospondin motifs) family during the last stages of development (days 15 and 21). Therefore, it seems that the balance and coordination among these factors might have a prominent role during both, early and late phases of adipocyte development.

In addition, cell shape and extracellular matrix remodeling have been found to regulate preadipocyte commitment and competency by modulating among others the RHOfamily GTPase signaling cascade in mammals [38]. Our data suggests that this could also be the case for rainbow trout adipocytes, due to the high number of genes of this family especially up-regulated during the early steps of the process. In this sense, cluster 1 was enriched with many representatives, such as Rho GTPase activating protein 22 (ARHGAP22) and 24 (ARHGAP24), Rho family GTPase 1 (RND1) and 3 (RND3), Rho GDP dissociation inhibitor beta (ARHGDIB), Rap guanine nucleotide exchange factor 1 (RAPGEF1), 2 (RAPGEF2) and 4 (RAPGEF4), Rho guanine nucleotide exchange factor 3 (ARHGEF3) and 4 (ARHGEF4) and T-cell activation RhoGTPase activating protein (TAGAP). Actin and myosin are examples of key molecules involved in cell shape mediated differentiation that are on the contrary up-regulated in late developmental phases [39].

In line with the dramatic cytoplasmic reorganization that occurs during adipogenesis, we found in the proliferation cluster the presence of Atg5, a key autophagy gene. Autophagy is a major cytoplasmic degradation pathway that has been linked to the regulation of adipogenesis in mammals [40]. It does not only participate in cellular remodelling, but it also plays an important role controlling the dynamic change in mitochondrial mass that takes place during the maturation process [41]. Loss of Atg5 results in impaired white adipose tissue development both, in vitro and in vivo in mice [42, 43]. In addition, transcripts encoding heat shock cognate protein of $70 \mathrm{kDa}$ (Hsc70) and lysosomal-associated membrane protein type 2A (LAMP2A), relevant proteins involved in chaperone-mediated autophagy [44], were increased in the cluster representing the differentiation phase, indicating that autophagy might be playing an important role during the whole differentiation process (Fig. 2d).

In humans, adipose-derived stem cells have been defined as one of the most promising stem cell types for its use in cell-based therapies to treat diverse diseases. This is due to the number of angiogenic and antiapoptotic growth factors that these cells secrete at bioactive levels. Adipogenesis and angiogenesis are known to be tightly associated in mammals [45], being angiogenesis required for adipose tissue expansion [46]. The angiogenic capacity of our cell system is early displayed (from day 8) (Fig. 2e), with the up-regulation of transcripts encoding some of the most relevant genes involved in this process, such as the hepatocyte growth factor (HGF), the 
vascular endothelial growth factor A (VEGFA) and the angiopoietin-related protein 4. (ANGPTL4). This suggests that, as in mammalian adipose-derived stem cells, which are reported to be involved in the regeneration of the ischemic myocardium [47], rainbow trout adipocytes may have also an active role in the regeneration of tissues.

\section{Coordinated expression of transcriptional factors during adipocyte differentiation \\ AP-1 complex}

A large number of transcription factors were upregulated with different temporal expression patterns over the course of rainbow trout adipocyte differentiation. Experiments using different cellular model systems have described the existence of a tightly regulated cascade of transcription factors that promote the differentiation of fat cells [4]. In white adipocytes this cascade starts with the activation of members of the activator protein-1 (AP-1) transcription factor complex [48]. AP-1 consists of dimers of proteins belonging to the Fos, Jun and activating transcription factor (ATF) families that have been reported to present different functional properties [49]. AP-1 works as an environmental biosensor of the cell, regulating different aspects of cell physiology in response to stress or growth factors [50]. During the first period of rainbow trout adipocyte development (Fig. 3a) we found the presence of c-Fos, which has been described as essential to initiate adipocyte differentiation and identified as part of a nuclear complex that regulates the expression of adipocyte-specific genes [51]. More recently, the ongoing differentiation process in 3T3-L1 cells was inhibited by the knockdown of this transcription factor [52], and in humans, a mutation in this gene has been associated with the development of congenital generalized lipodystrophy [53]. We also found the transcription factor FOS-like antigen 2 (FOSL2, also referred to as Fra2) highly expressed during the first stages of cell development (Cluster 1). Even though this transcription factor is not considered as adipocyte-specific, it has been described to promote the expression of the adipokine leptin in both, human and mouse adipocytes [54]. In addition, its implication in adipocyte homeostasis has been evidenced since its deletion triggers a high adipocyte turnover able to regulate body fat mass in mice [55]. On the other hand, other transcription factor from the AP-1 complex, the protein FosB was also upregulated during the same period. The overexpression of this gene has been reported to provoke inhibition of adipogenesis in mice and is suggested to exert this action through an interaction with C/EBP $\beta$ [56]. Interestingly, several members of the ATF family (ATF2, ATF3, ATF4, ATF5, and ATF6B) were found overexpressed only during the differentiation phase of the rainbow trout culture. Many of these genes are known to mediate cellular stress response signalling; and for instance ATF3 has been recently involved in adipocyte differentiation although it appears to have an inhibitory action, suggesting that a coordinated equilibrium between members of the different families that conform the AP-1 complex would be necessary [57]. Overall, the parallelism of gene expression profiles in mammalian models and the present study in AP-1 components suggests a similar role of this transcription factor complex in fish, with some speciesspecific responses. In this sense, a different temporal activation of this complex was reported in Atlantic salmon adipocytes, where the induction of AP-1 was observed during the last stages of adipogenesis [14].

\section{E2F, C/EBP, Krüppel-like factor (KLF) and GATA families}

The E2F family of transcription factors is known to regulate cell cycle progression [7] as well as adipocyte differentiation [58]. In our study we found E2F4 highly expressed at day 3 of the culture, and then the expression went down (Fig. 3b). In mammals, E2F4 forms a complex with RBL2 that is able to repress the transcription of PPAR $\gamma$, and then is lost after hormonal stimulation to allow adipogenesis to proceed [59]. We observed that E2F4 and RBL2 follow the same expression pattern during rainbow trout adipocyte development (Figs. 2a and $3 \mathrm{~b}$ ), suggesting that their down-regulation might be required to promote adipogenesis also in this species. Likewise, the recently reported novel regulator of proadipogenic genes, zinc finger protein 638 (ZNF638) [60] was induced early during rainbow trout adipocyte development, presenting its peak of expression at day 3 as well as the early growth response protein 2 (EGR2, also known as KROX20), which has been described as a factor capable of inducing uncommitted fibroblasts to become adipocytes [61].

During rainbow trout adipogenesis we also identified a transient induction of several members of the C/EBP family of transcription factors (Fig. 3b). C/EBP $\delta$, which is a key early regulator of adipogenesis, presented its peak of expression at day 3 of cell development. C/EBP $\delta$ together with $C / E B P \beta$, have been reported to transactivate $\mathrm{CEBP} \alpha$ [62]. In our cell system, CEBP $\alpha$ started to be up-regulated from day 8 , with a maximum peak at day 15. This transcription factor, together with PPAR $\gamma$, is known to coordinate and induce the expression of several genes involved in insulin sensitivity, lipogenesis and lipolysis promoting the adipocyte phenotype [63]. Immunofluorescence results showed a high presence of both transcription factors, CEBP $\alpha$ and PPAR $\gamma$, in rainbow trout differentiating adipocytes at day 11 , suggesting their implication in the regulation of these processes [5], as supported now by the present results.

Several members of the multigenic Krüppel-like factor (KLF) family have been reported to control adipogenesis, 


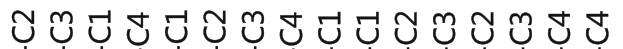
ติ่

a

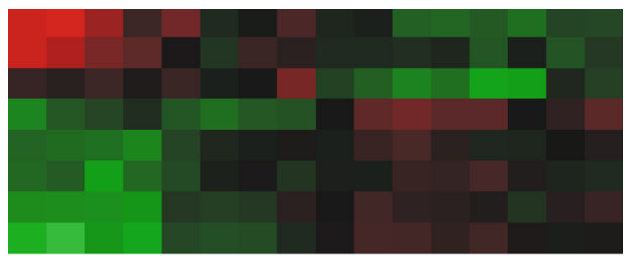

b

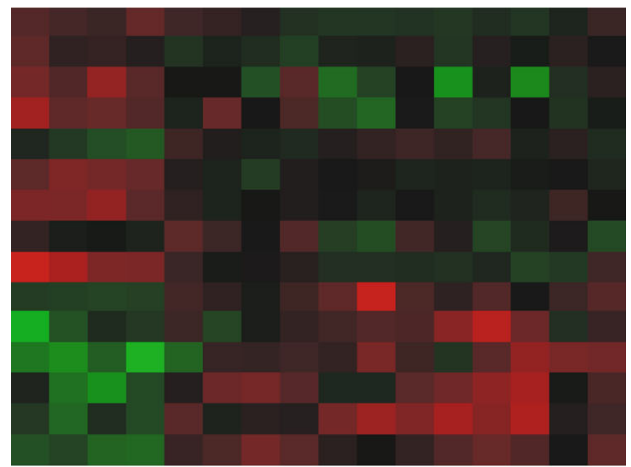

C

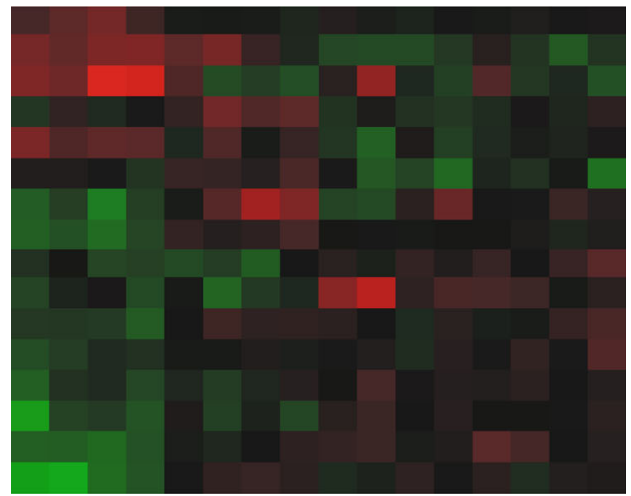

Proto-oncogene c-Fos

Protein fosB

Fos-like anigen 2

ATF2

ATF3

ATF4

ATF5

ATF6B

E2F4

ZNF638

EGR2

C/EBP $\delta$

$\mathrm{C} / \mathrm{EBP} \alpha$

KLF 2

KLF 4

KLF 6

GATA-binding factor 2

KLF11

KLF15

KLF16

GATA-binding factor 5

GATA-binding factor 6

MAF

Hox-A5

Hox-A10

HoxB9

Hox-D10

CDX-1

ZEB1

MOX-2

SIX-1

$\mathrm{HMX1}$

$\mathrm{HMX} 2$

PITX1

Hox-C9

IRX5

HESX1

SIX-2

DLX3B

Fig. 3 Selected transcriptional regulators overexpressed during rainbow trout adipogenesis. a AP-1 complex; b E2F, C/EBP, Krüppel-like factor and GATA families; c Homeobox containing transcriptional factors

some being considered activators (KLFs 4, 5, 6 and 15) while others are considered repressors of transcription (KLFs 2 and 7) [48, 63]. During the progression of our culture we observed a sequential expression of members of this family (Fig. 3b). Thus, during the early stages of cell development we identified transcripts encoding the KLFs 2, 4 and 6, while transcripts encoding the KLFs 11, 15 and 16 were present during adipocyte maturation. Some of them have been extensively studied in the context of adipocyte progression. For instance, KLF4 has been described as an essential early activator of adipogenesis able to bind to Krox20 to transactivate C/EBP $\beta$ [64]. KLF15 is known to play an important role in adipocyte insulin sensitivity through the transactivation of the facilitative glucose transporter (GLUT4) promoter by binding near the myocyte enhancer binding factor-2A (MEF2A) consensus site [65]. Less is known about the roles of this family of transcription factors in fish. In
Fugu, a potential binding site for KLF15 and MEF2 has been identified also in the GLUT4 promoter region, indicating a remarkable conservation among vertebrates [66]. In zebrafish, several members have been identified and characterized, and a high degree of functional conservation with the mammalian homologs was reported [67] with a special focus on the function of these factors in hematopoiesis [68]. On the other hand, an important role of this family of proteins in rainbow trout oogenesis has been suggested, being this a conserved feature among vertebrates [69]. Therefore, and in light of our transcriptomic data, we could speculate that the KLF family plays a critical function during rainbow trout adipogenesis with some of their actions maintained during evolution from fish to mammals.

GATA factors are generally considered as negative regulators of adipogenesis. We found GATA2 up-regulated during proliferation (Fig. $3 \mathrm{~b}$ ), with a significant peak of 
expression at day 3. This is in agreement with previous findings reported in the mammalian system, where the expression of this transcription factor is restricted to the preadipocyte phase and is down-regulated upon adipocyte differentiation [70]. Two other members from this family were significantly expressed during rainbow trout adipogenesis with different expression patterns, GATA5 and GATA6 (Fig. 3b); however, to the best of our knowledge the implication of these members in adipogenesis has not been reported so far.

As previously mentioned, adipocyte development is regulated by a network of multiple transcription factors, and $\mathrm{V}$-maf avian musculoaponeurotic fibrosarcoma oncogene homolog (MAF) is likely to be involved in coordination with other factors [71]. The expression of MAF has been reported to increase during human adipogenesis [72] and this seems to be the case in rainbow trout culture, since its transcript abundance was increased from day 8 post-seeding.

\section{Homeobox genes}

Furthermore, with regards to other transcription factors involved in adipogenic differentiation, we also found a large number of transcripts encoding homeoboxcontaining genes that were differentially regulated (Fig. 3c). During the early stages of adipocyte development several Hox family genes, such as HoxA5, HoxA10, HoxB9 and HoxD10 were up-regulated. Hox genes are responsible for embryonic and adult development [73] and even though they have been reported to be involved in the adipogenic process of different model systems [74, 75], their expression pattern differs depending on the localization of fat depots within the human body [76]. Transcripts from four other homeoboxcontaining factors were present during the proliferative phase; mesenchyme homeobox 2 (MEOX2), SIX homeobox 1 (SIX1), caudal type homeobox 1 (CDX1) and zinc finger E-box-binding homeobox 1 (ZEB1). Interestingly, ZEB1 has been recently described as a key transcriptional component in the regulation of mouse pre-adipocytes development among other functions [77]. The second phase of rainbow trout adipogenesis was also characterized by the presence of many transcripts belonging to these groups of proteins. Among them we found up-regulated in the differentiation cluster: H6 family homeobox 1 (HMX1) and 2 (HMX2), paired-like homeodomain 1 (PITX1), homeobox C9 (HoxC9), iroquois homeobox 5 (IRX5), HESX homeobox 1 (HESX1), SIX homeobox 2 (SIX2) and distal-less homeobox 3b (DLX3B). The implication of homeobox transcription factors as relevant players in the regulation of adipose tissue functions have been recently reported [78]. The strong enrichment of these kinds of genes during rainbow trout adipogenesis could therefore indicate that they are also relevant molecules regulating adipose tissue development in fish.
All in all, a sequential activation of different transcription factors is present during the transformation of precursor cells into fully differentiated mature adipocytes in rainbow trout. Moreover, the general progression found seems to be very similar to that already described in different mammalian models, although functional studies of some of these factors would reveal possible fishspecific roles during adipogenesis.

\section{Epigenetic factors during adipogenesis}

The dynamic remodeling of chromatin and its influence on adipogenic gene expression has been previously reported in other cell systems [79-81]. Histone modifications are relevant mechanisms to study since they are known to modulate the transcriptional regulation of factors that govern adipogenesis. However, these kinds of processes have not been explored in fish adipocytes so far.

Our results suggest that there is an important link between transcriptional regulation and epigenetic modulation. We have found a large number of up-regulated genes encoding epigenetic transcriptional regulators, especially during the proliferation phase (Fig. 4). We detected several histone-lysine $\mathrm{N}$-methyltransferases, such as enhancer of zeste 2 polycomb repressive complex 2 subunit (EZH2), lysine (K)-specific methyltransferase 2A (MLL), DOT1-like histone H3K79 methyltransferase (DOT1L) and SET domain, bifurcated 1 (SETDB1). Surprisingly, SETDB1 is one of the methyltransferases known to inhibit adipogenesis by repressing PPAR $\gamma$ [82]. On the contrary, EZH2 has been described to present pro-adipogenic activity, since it silences Wnt genes, which are known to be negative regulators of adipogenesis [83]. Other genes coding for proteins involved in chromatin remodeling during the first stages of adipocyte development are the histone-arginine methyltransferase CARM1, the histone acetyltransferase MYST2 and the histone deacetylase 10 (HDAC10), SWI/SNF related, matrix associated, actin dependent regulator of chromatin,

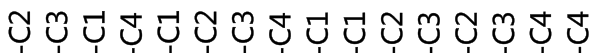

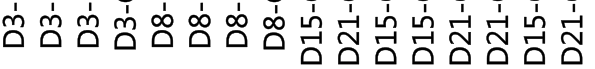

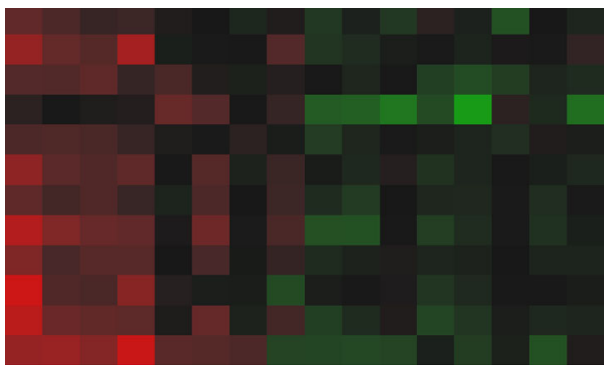

$\mathrm{EZH} 2$

MLL

DOT1L

SETDB1

CARM1

MYST2

HDAC10

SMARCC2

PCGF1

PCGF6

PHF12

PHF19

Fig. 4 Epigenetic transcriptional regulators overexpressed during the proliferative phase of rainbow trout adipocyte development 
subfamily c, member 2 (SMARCC2), and members of the Polycomb group (PcG) of proteins such as PCGF1, PCGF6, PHF12 and PHF19.

\section{Specific regulatory systems Insulin and IGF system}

The insulin and IGFs system plays a critical role in mammalian adipocyte models. Insulin, IGF-I and IGF-II expression did not change along the rainbow trout cell culture; however, differential patterns of expression were observed for several IGF binding proteins (IGFBPs). IGF 2 mRNA-binding protein 3 (IGF2BP3), which has been described as a translational activator of IGF-II and further leads to the activation of its immediate downstream effectors promoting proliferation and angiogenesis [84] was up-regulated during the proliferation phase (Fig. 5). IGFBP4 and IGFBP7 were up-regulated during differentiation, while IGFBP5 decreased (Fig. 5). IGFBPs can inhibit and/or potentiate IGF actions, depending on the cellular context and experimental conditions [85]. In vascular smooth muscle cells, when added together with IGF-I, IGFBP4 exerts an inhibitory effect on IGF-I-induced DNA synthesis, while IGFBP5 potentiates the mitogenic effect of IGF-I, which is in concordance with the expression profile of IGFBPs observed in our study. Besides, some IGFBPs such as IGFBP3 and IGFBP5 have been also shown to have intrinsic biological activities that are IGFindependent $[86,87]$. In this sense, IGFBP3 inhibits both 3T3-L1 preadipocyte differentiation initiated by insulin as well as insulin action in differentiated adipocytes. Although no changes in IGFBP3 were observed in our cells, a decline in IGFBP5 was found during the differentiation phase as it has been reported in porcine cells [88].

Moreover, insulin and IGF-I receptors did not show significant variations along the culture but regarding its signaling pathway, insulin receptor substrate 1 (IRS1) was up-regulated during proliferation (Fig. 5). IRS-1 and IRS-2 have multiple tyrosine residues, which are used as 'docking' sites for downstream signaling molecules and are linked to differential processes [89]. IRS-1 mediates both metabolic and proliferative effects of IGF-I, but its mitogenic actions are more relevant [89, 90], which agrees with its higher expression during the proliferative

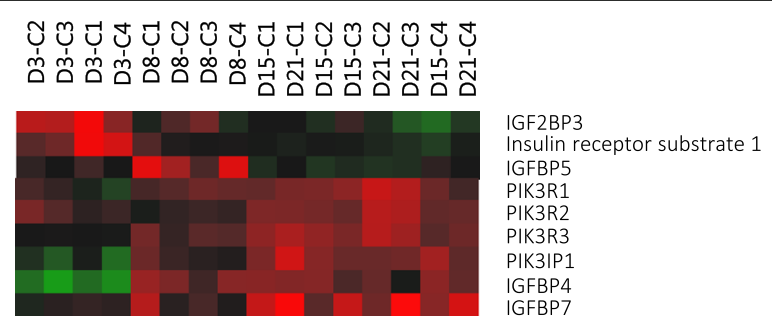

Fig. 5 Selected genes involved in the insulin and IGF system overexpressed during rainbow trout adipogenesis phase of our culture compared to the differentiation phase. Several genetically altered mouse models of IGF-I signaling provide clues to understanding the role of this growth factor in adipogenesis. A point mutation in the IRS-1 gene induced growth retardation and reduced the amount of adipose tissue in mice [91].

Key components of the insulin and IGF-I signaling cascade such as phosphatidylinositol 3-kinase regulatory subunits alpha (PIK3R1), beta (PIK3R2), gamma (PIK3R3) and phosphoinositide-3-kinase-interacting protein 1 (PIK3IP1) were up-regulated during differentiation (Fig. 5). This regulation agrees with the fact that this pathway activates metabolic processes, abundant during adipocyte maturation in these later phases being for instance key signaling molecules in the stimulation of glucose uptake. Human preadipocytes, as is the case for murine preadipocytes, depend on it to undergo complete differentiation [92].

\section{Eicosanoid metabolism}

Arachidonic acid (AA) is a polyunsaturated omega-6 fatty acid that is released from the membrane phospholipids by the activity of the cytosolic phospholipase A2 (cPLA2). Then, free AA can be metabolized to eicosanoids through three major routes: the lipoxygenase (LOX), the cyclooxygenase (COX) and the cytochrome P450 (CYP) pathways. These signalling pathways are relevant for adipocyte development, since some of its products have been reported to activate lipid biosynthesis during the acquisition of the adipocyte phenotype [93] and are implicated in other functions related to immune response and inflammation. In line with this, the relevance of the activation of different immune pathways during Atlantic salmon adipogenesis has been previously reported [14]. During the early steps of adipocyte culture, we found up-regulated different genes encoding members of the PLA2 class of enzymes (Fig. 6a), such as PLA2G4A and PLA2G1B, pointing out to the early implication of eicosanoid metabolism in the process of rainbow trout adipocyte development. This is in agreement with the results from the functional analysis performed, where the eicosanoid signaling pathway was highlighted during the proliferative phase of the culture. In mammals, eicosanoids are known to serve as natural ligands to activate PPARs [94]; whether fish adipocytes activate the eicosanoid metabolic pathway to also regulate PPARY remains unknown.

A critical function of LOX activity in the early steps of mammalian adipocyte development has been reported, since there are enough evidences supporting that LOXderived endogenous products might be also ligands involved in the transactivation of PPAR $\gamma$ [95]. Interestingly, and in agreement with these findings, the search of LOX genes in the microarray data only presented results during the proliferative phase. In the transcriptome 


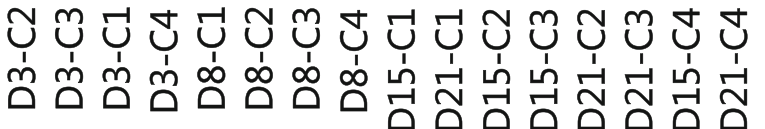
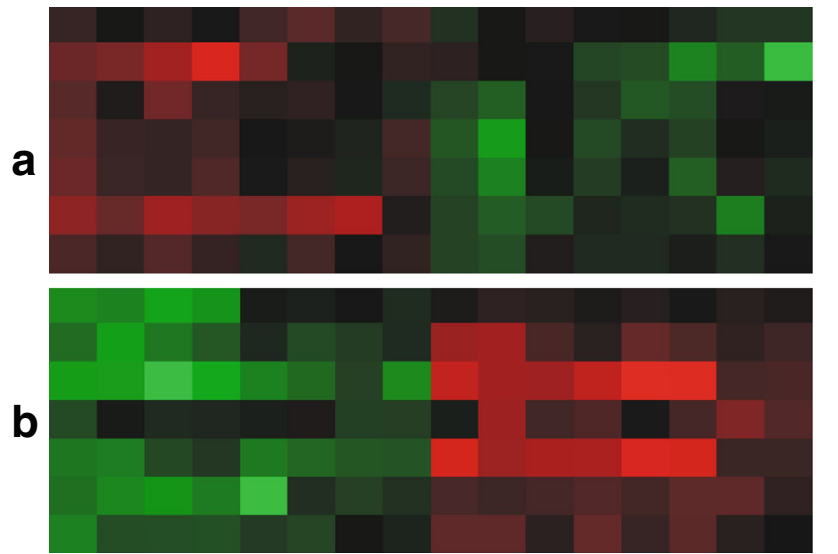

PLA2G4A

PLA2G1B

ALOX5

ALOX15B

ALOX12

PTGS1

PTGER1

HPGD

AKR1B1

CYP2J1

CYP2J5

CYP2J6

CYP2C5

$\mathrm{PHX} 2$

Fig. 6 Selected genes involved in eicosanoid metabolism. a Genes overexpressed during the proliferative phase; b Genes overexpressed during the differentiation phase

data we found an up-regulation of the genes arachidonate lipoxygenases ALOX5, ALOX15b and ALOX12 during days 3 and 8 of the culture (Fig. 6a); all of which have been reported to be implicated in mammalian development of the adipocyte [96].

AA metabolites from the COX pathway formed by 3T3-L1 adipocytes have been reported to regulate the progression of adipogenesis through an autocrine control mechanism [97, 98]. The identification of several genes involved in the COX pathway exhibiting significant changes in expression during rainbow trout adipogenesis is stressing the possible implication of this pathway in the adipocyte maturation process. Thus, in the cluster associated with proliferation we found up-regulated prostaglandin G/H synthase 1 (PTGS1; also known as COX1) and prostaglandin E2 receptor EP1 subtype (PTGER1) (Fig. 6a). During the differentiation phase other genes implicated in the metabolism of prostaglandins were present, such as 15-hydroxyprostaglandin dehydrogenase [NAD+] (HPGD) and the aldose reductase AKR1B1 (Fig. 6b), as it was recently shown in human multipotent adipose-derived stem cells [99].

In the CYP pathway, AA is converted to epoxyeicosatrienoic acids (EETs) and 20-HETE by CYP epoxygenases and CYP $\omega$-hydroxylases, respectively [100]. EET biosynthesis can be accomplished by different P-450 isozymes, being the members of the CYP2J and CYP2C epoxygenases of especial relevance in this process. Then, EETs are rapidly hydrolyzed by soluble epoxide hydrolase (EPHX2) to form less active dihydroxyeicosatrienoic acids (DHETs). In this sense, the microarray data revealed a remarkable presence of different members of these genes overexpressed during the differentiation phase such as
CYP2J1, CYP2J5, CYP2J6, CYP2C5 and EPHX2 among many others (Fig. 6b). A dysregulation of the CYP epoxygenase pathway has been recently reported to be a pathological consequence of obesity [101], emphasizing the importance of the bioavailability of EETs for a healthy and functional adipose tissue.

\section{Terminal differentiation regulators}

As soon as the cells start to present an adipocyte-like phenotype (days 15 and 21), a remarkable number of genes critical for many aspects of carbohydrate and lipid metabolism were overexpressed in comparison with previous stages (days 3 and 8). Regarding the activation of the carbohydrate metabolism, we identified and selected for further validation the gene encoding one of the main enzymes controlling gluconeogenesis; phosphoenolpyruvate carboxykinase 1 (PEPCK). Some other selected genes were also tested by qPCR (see Fig. 9). The development of one of the main functions of adipocytes, which is its high capacity to store energy, was highlighted by the large presence of genes involved in metabolic trapping, glycogen synthesis, the pentose phosphate pathway, glycolysis, oxidative phosphorylation and all aspects of lipogenesis. On the other hand, the differentiation phase was also characterized by up-regulation of genes required for regulating the mobilization of stored energy, corroborating one of the basic roles of adipocytes, being a buffer tissue storing and providing energy depending on body demands.

Alongside the development of the machinery involved in lipid and carbohydrate metabolism, the activation of the thyroid-receptor/retinoic X receptor (TR/RXR) and the PPAR signalling pathways was observed during the differentiation phase (Additional file 3). Both, PPARs 
and TRs exert their activity partly by heterodimerization with RXR and they are known to play key roles in lipid mobilization, lipid degradation, fatty acid oxidation, and glucose metabolism [102]. In mammals, PPARs and TRs can crosstalk to regulate different cellular processes including adipogenesis [103]. The functional annotation analysis in the present study suggests that this might also be the case for rainbow trout adipocytes.

\section{Fatty acid transport and oxidation during adipocyte maturation}

The expression of proteins involved in fatty acid transport were mainly expressed during differentiation. We observed a high representation from the fatty acid binding protein family (FABPs) (Fig. 7a). Only FABP2 was up-regulated during proliferation, whilst FABP1, FABP3, FABP4 (which is predominantly expressed in mammalian adipose tissue) [104], FABP6 and FABP7 were all up-regulated during differentiation. The increasing levels of FABPs point out to the mobilization of fatty acids to mitochondria and peroxisomes for energy production. In mammals, FABPs are recognized as important signalling molecules with effects not only on the systemic energy metabolism but also on inflammatory processes [105]. In this sense, FABP4 acts as an adipokine regulating adipocyte and macrophage interactions during inflammation [106]. FABP3 transcripts have been predominantly detected in subcutaneous adipocytes [107] and intraperitoneal adipose tissue of rainbow trout [23]. The high presence of FABPs suggests an important role for this family of proteins during the maturation process of fish adipocytes. In mammals, it has been reported that some FABPs significantly cooperate with PPARs [108]. Further studies focusing on the mechanisms of action of these proteins should be performed in fish in order to determine their function in the adipocyte biology.

After transport, fatty acids can be activated to the respective acyl-CoA esters by one of the acyl-CoA
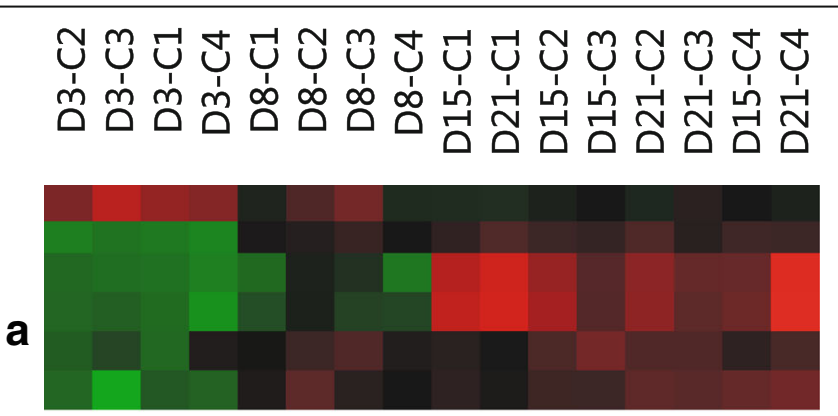

FABP2

FABP1

FABP3

FABP4

FABP6

FABP7

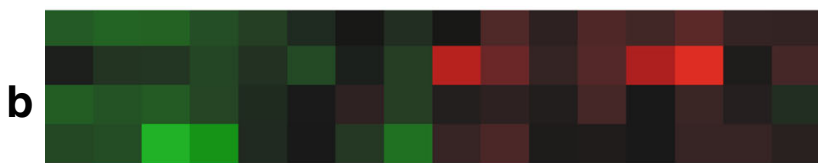

ACSL1

ACSL4

ACSL6

SLC27A3

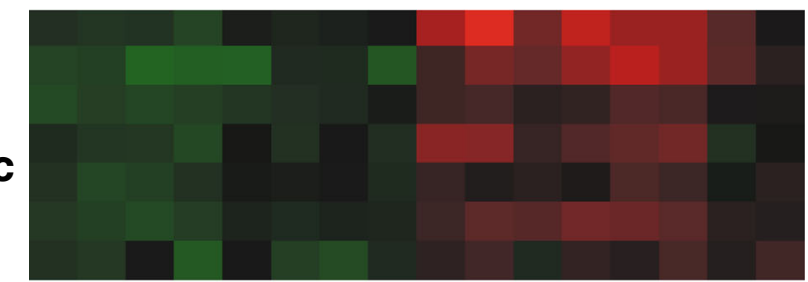

AGPAT4

AGPAT5

AGPAT9

DGAT1

G6PDH

IDH3G

IDH2

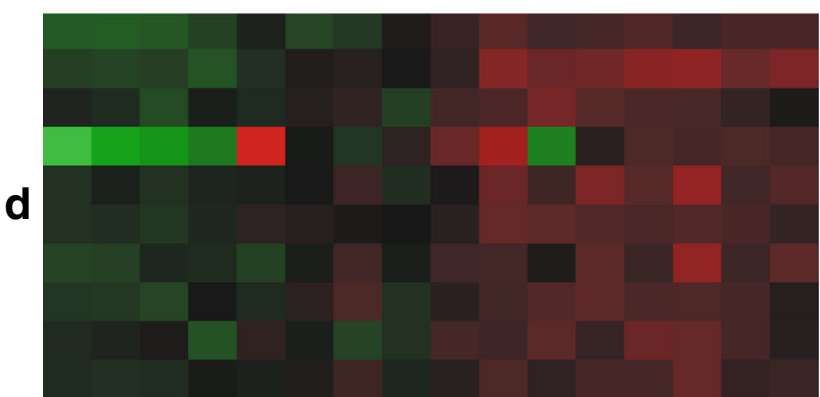

CRAT

CROT

ACOX3

UCP2

ACADL

ACADM

ACADS

$\mathrm{HADH}$

$\mathrm{HCD} 2$

ACAA2

Fig. 7 Selected genes involved in lipid metabolism. a Fatty acid transporters; b Acyl-CoA synthases; c Genes coding proteins involved in the synthesis of lipids; d Genes involved in energy production 
synthetases. In this sense, we found a strong enrichment of genes encoding several members of long chain fatty acid acyl-CoA synthetases in the differentiation cluster (Fig. 7b), such as ACSL1, ACSL4 and ACSL6, as well as the long-chain fatty acid transport protein 3 (SLC27A3). The presence of different ACSL isoforms might be essential for adipocyte function since they assure the channelling of fatty acids towards degradation or lipid biosynthesis depending on the energetic status of the cell.

A salient feature of the differentiation cluster was the presence of many genes encoding enzymes responsible of catalysing different steps along the triglyceride biosynthetic pathway (Fig. 7c). Such is the case for several members of the 1-acylglycerol-3-phosphate O-acyltransferase family (AGPAT4, AGPAT5 and AGPAT9) and the diacylglycerol O-acyltransferase 1 (DGAT1). In addition, genes involved in the production of reducing power for the synthesis of lipids, such as glucose- 6 phosphate dehydrogenase (G6PDH) and isocitrate dehydrogenase (ICDH) were also present.

The activation of mechanisms responsible of providing energy to the adipocyte were also evidenced during the last stages of culture development (Fig. 7d). In this sense, proteins involved in the oxidation of fatty acids were present in the differentiation cluster, such as carnitine O-acetyltransferase (CRAT) and carnitine Ooctanoyltransferase (CROT). These two enzymes convert the end products of the peroxisomal $\beta$-oxidation $(\mathrm{C} 8$ or C6-CoA) to acylcarnitines so they can be transported out of the peroxisomes and be further oxidized to acetyl-CoA in the mitochondria. We also found upregulated during differentiation the expression of peroxisomal acyl-coenzyme A oxidase 3 (ACOX3), which is involved in the desaturation of 2-methyl branched fatty acids in peroxisomes. The expression of ACOX3 has been linked to a possible pathway for metabolism of phytanic acid and pristanic acid in peroxisomes in white adipose tissue [109]. In mammals it is known that $\beta$ oxidation of fatty acids can take place in both, mitochondria and peroxisomes, serving different functions in the cell [110]. The transcript abundance of other protein involved in lipid oxidation, like the mitochondrial uncoupling protein 2 (UCP2), was increased from day 8 . This protein reduces the ATP yield and may facilitate the oxidation of fatty acids [111]. Many other genes involved in mitochondrial fatty acid beta-oxidation were present, such as acyl-CoA dehydrogenase, long chain (ACADL), acylCoA dehydrogenase, $\mathrm{C}-4$ to $\mathrm{C}-12$ straight chain (ACADM), acyl-CoA dehydrogenase, $\mathrm{C}-2$ to $\mathrm{C}-3$ short chain (ACADS), hydroxyacyl-CoA dehydrogenase (HADH), 3-hydroxyacylCoA dehydrogenase type-2 (HCD2) and acetyl-CoA acyltransferase 2 (ACAA2) among many others.

Overall, according to the functional characteristics of the mature adipocyte, genes involved in fatty acid transport, lipid synthesis and oxidation were the most relevant in late differentiation phase. The activation of diverse genes with redundant functions might be directed to provide different mechanisms to accomplish and ensure the proper function of mature differentiated adipocytes.

\section{Lipid droplet formation}

Mature white adipocytes are characterized by the presence of a large unilocular lipid droplet that occupies the majority of the cell. A critical aspect of adipocyte development is the formation and expansion of such lipid droplet within the cell. The storage of triglycerides within the lipid droplet allows the correct expansion of the adipose tissue while preventing lipotoxicity in other organs [112]. Therefore, lipid droplets are considered to be crucial organelles in the regulation of energy homeostasis and in the prevention of insulin resistance [113]. In the differentiation cluster we found up-regulated some of the well-known structural proteins that constitute the surface of the lipid droplets (Fig. 8a). Such is the case of the fat-specific protein 27/Cidec (FSP27) and Cavelin-1. Even though these proteins are not considered to be essential for adipocyte differentiation, their key role in lipid droplet formation has been recognized and thus also, in the acquisition of the adipocyte phenotype $[114,115]$. Apart from their importance as structural proteins they have been described to play an important role in insulin signalling $[46,113]$. Moreover, we also found highly expressed transcripts of the vesicleassociated membrane protein 4 (VAMP4), a member of the SNARE family known to be involved in the growth of lipid droplets via fusion [116]. Another protein that has been recently associated to lipid droplets, the microsomal triglyceride transfer protein (MTP), was also present in the differentiation cluster. This protein, which is known to be essential for lipid transport, has been reported to be present in the same droplets as perilipin 2 (PLIN2) [117]. Our results showed that PLIN2 exhibited the same pattern of expression as MTP, with significantly higher abundance of transcripts present during the differentiation phase of rainbow trout adipocytes. The study of specific mechanisms concerning the formation and turnover of lipid droplets would be of high value in order to elucidate the function of different associated proteins in lipid droplet biology in fish adipocytes.

\section{Redox homeostasis}

Adipocyte expansion and consequently lipid droplet growth, represents a healthy way of disposing excess of fat in the form of neutral lipids. Even though a continuous or extreme expansion can represent a challenge to adipocytes leading to the production of reactive oxygen species and endoplasmic reticulum stress [112], a moderate generation of reactive oxygen species has been described as a factor promoting adipocyte differentiation 


\section{ソํㅓㄴ

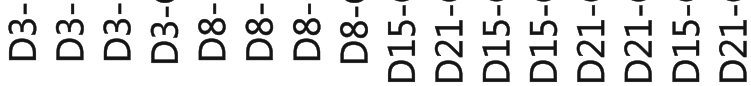

a

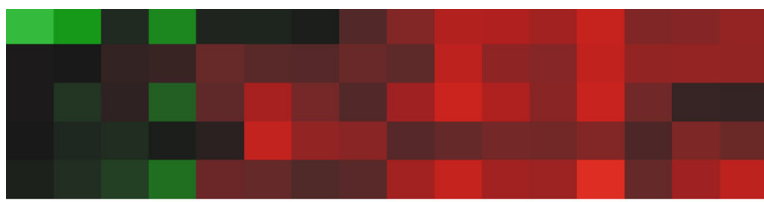

FSP27

Cavelin-1

VAMP4

MTP

PLIN2

b

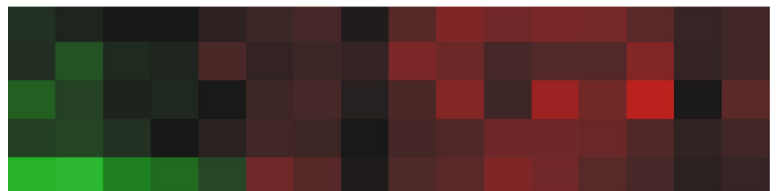

GPX1

GPX2

GSTD1

GSTT4

NRX

Fig. 8 Selected genes highlighted during the terminal phase of adipocyte development. a Lipid droplet formation; b Antioxidant system

[118]. Therefore, the control of redox homeostasis in the intracellular environment is key for adipogenesis to progress. In line with this, we identified few genes encoding antioxidant enzymes (Fig. 8b), such as glutathione peroxidase 1 and 2 (GPX1 and GPX2), glutathione S-transferase 1, isoform D (GSTD1) and glutathione S-transferase theta-4 (GSTT4), all of them induced during the lipidloading phase. The modulation of intracellular glutathione has been reported to affect adipogenesis in 3 T3-L1 cells [119]. In addition, the importance of the activation of the gluthatione-based antioxidant system in Atlantic salmon adipocytes has been recently highlighted [14]. Likewise,

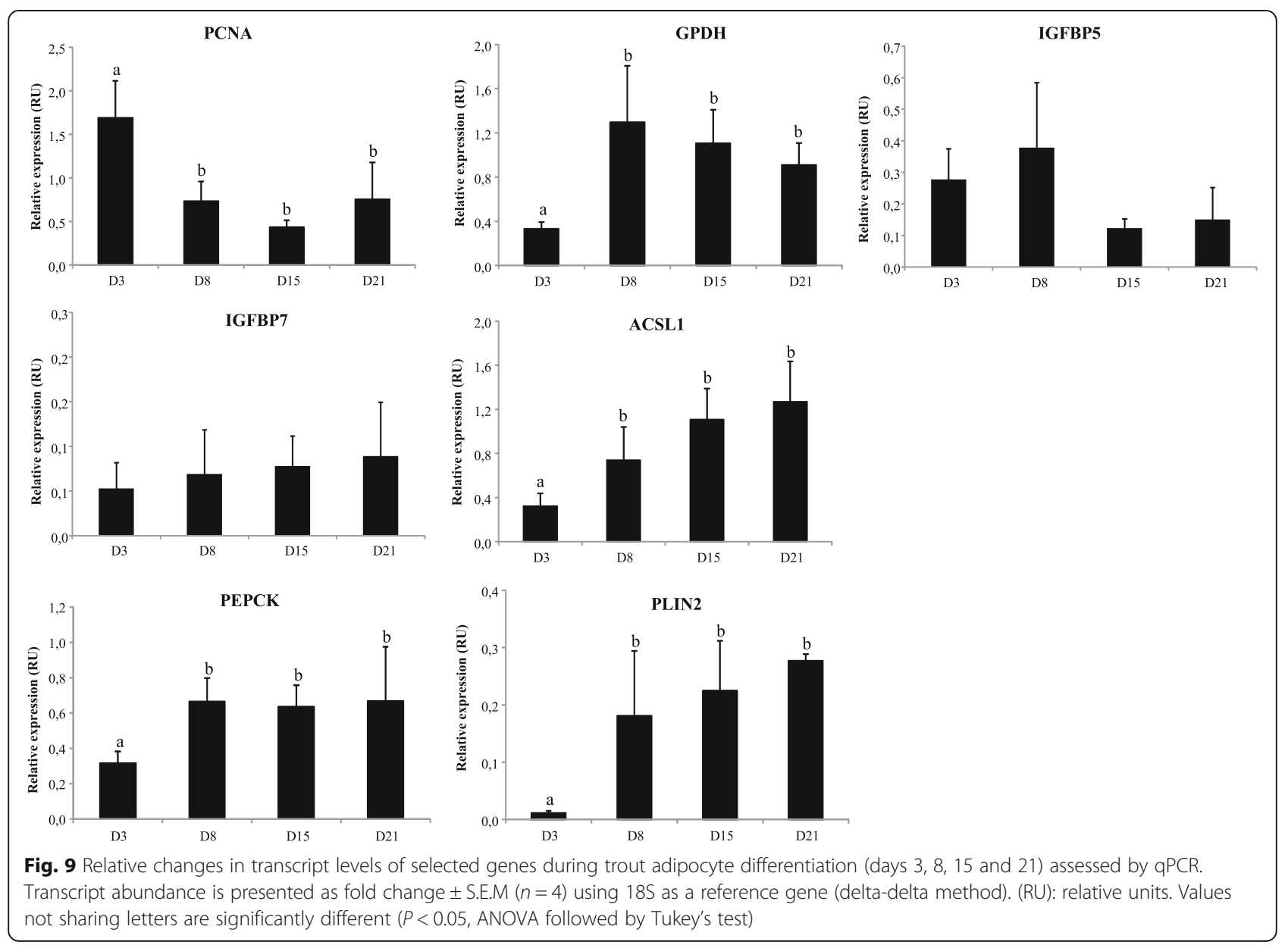


nucleoredoxin (NRX), a member of the thioredoxin family of proteins known to control redox homeostasis in the cell, followed the same regulation in rainbow trout adipocytes. Interestingly, NRX has recently been described as a novel pro-adipogenic factor [120].

\section{Temporal profile analysis of mRNA (qPCR) and protein expression}

The expression profile along the culture of some selected genes was tested using qPCR (Fig. 9). The genes were selected on the basis of showing differential expression, their novelty in fish or their relevance and implication in the already described mammalian adipogenic process. Despite of the activation of ribosome biogenesis during the early phase of adipocyte development, $18 \mathrm{~S}$ was found to be the most stable reference gene, suggesting that some regulatory proteins involved in this process other than $18 \mathrm{~S}$ might be differentially regulated. Additionally, and despite the potential confounding effect of normalizing to a reference gene, both the relative abundance of the target genes prior to normalization and the transcriptomic data supports the presented values. The levels of protein of some of the selected genes were also tested, in order to assess whether the protein encoded by a specific mRNA and its expression showed a similar profile (Fig. 10). Both qPCR and Western blot analysis reinforced the data obtained in the microarray analysis. The high proliferative capacity of the cells during the early stages determined by the gene expression pattern of proliferating cell nuclear antigen (PCNA), which had its highest peak in the transcriptome at day 3 of rainbow trout adipocyte development, was further reinforced by qPCR and Western blot analysis. Likewise, the maturation state of the cells was confirmed by both, microarray and qPCR measures of glycerol-3-phosphate dehydrogenase (GPDH). In addition, the transcript abundance of two IGFBPs aforementioned, IGFBP5 and IGFBP7, were analyzed by qPCR. Despite of the lack of significance, IGFBP5 followed the same pattern as the one observed in the microarray, while the mRNA of IGFBP7 remained fairly static along the culture according to qPCR results. Moreover, two genes representing the development of lipid and

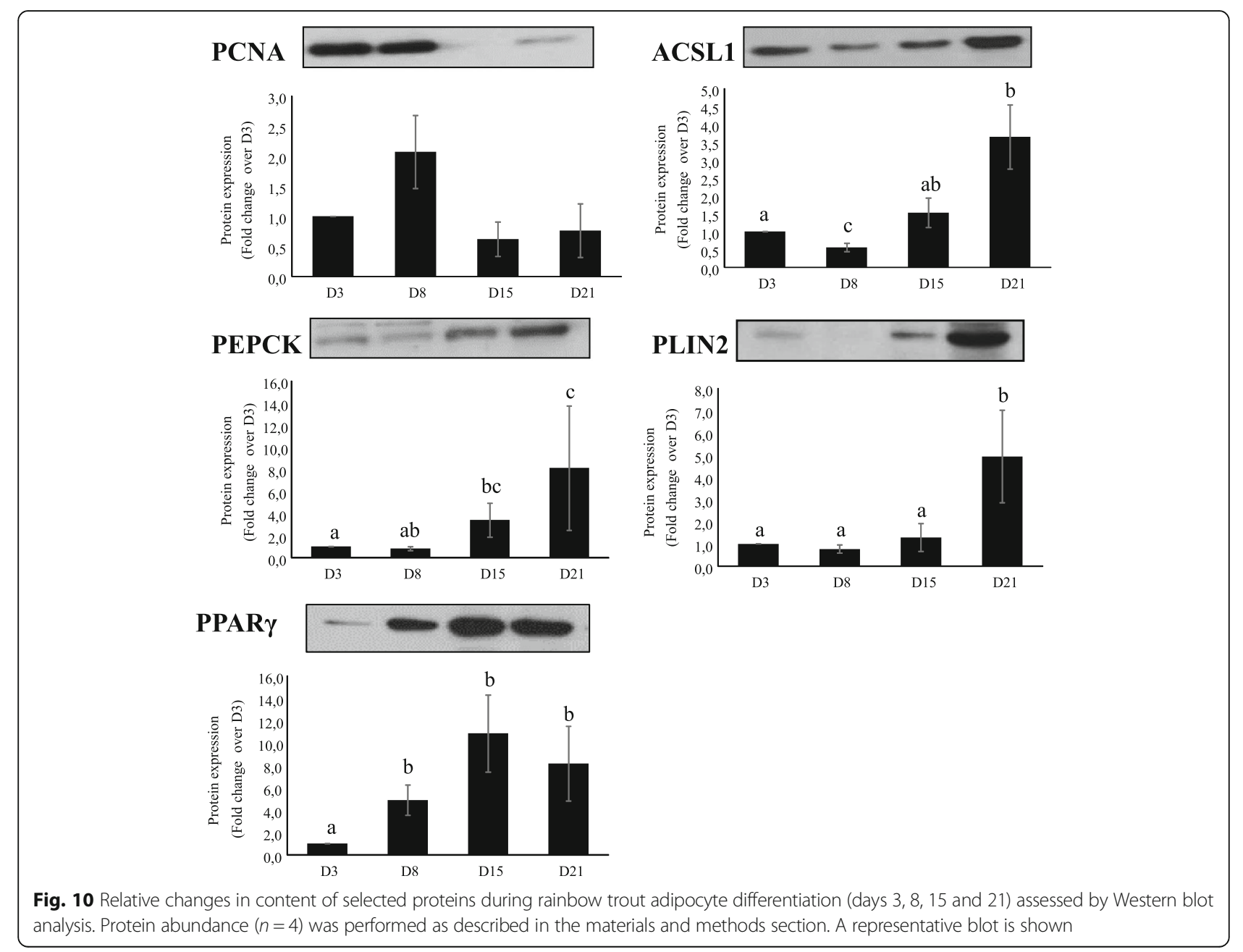


carbohydrate metabolism, ACSL1 and PEPCK respectively, were assessed as well by qPCR and Western blot, confirming the specialization of the cells towards mature adipocytes showing higher levels of expression at later days and validating the microarray results. In addition, PLIN2 was also evaluated through all three techniques, exhibiting a higher abundance during the differentiation phase and suggesting thus the involvement of this structural protein in the maturation process of our cell system. It should be noted that, as far as we know, no member from the perilipin family has been characterized in fish until now. Therefore, the expression and function of this gene deserves further studies. On the other hand, the protein levels of PPARy, which is considered the master regulator of adipogenesis, were significantly increased from day 8 and maintained up to day 21 . Therefore, confirming the relevance of the PPAR signaling pathway during the differentiation phase revealed by the transcriptomic analysis and previous studies [5].

Likewise, as we have described in the present paper, many other key molecules known to be involved in the adipogenic process of mammalian preadipocyte cell lines, also changed in the same direction in our culture system. Therefore, these kinds of approaches can be seen as an extra validation of the microarray results.

\section{Conclusions}

This study was performed in order to gain a comprehensive view of the regulatory mechanisms involved in the process of fat cell development in fish. Our cell system presents a high similarity with the already described process of adipocyte differentiation in mammalian models, with abundance of several of the pro-adipogenic transcription factors and many of the mature adipocyte related genes. As it is evidenced by the large number of genes transcriptionally regulated in this study, fish adipogenesis is a complex and tightly coordinated process.

In mammals, adipocyte dysregulation has been linked to the development of metabolic diseases and therefore remarkable efforts are being done to understand the intricacies of adipogenesis. Many aspects concerning the biology of fish adipose tissue and its contribution to the balance of the overall energy homeostasis remain unexplored. This study provides an important base for further research. However, functional approaches will be needed in order to clarify the role of the genes highlighted in the present work.

\section{Additional files}

Additional file 1: Significant biological functions associated with the proliferative phase of adipogenesis determined by IPA software. (XLSX $13 \mathrm{~kb}$ )

Additional file 2: List of genes from the highlighted biological functions associated with the proliferative phase of adipogenesis determined by IPA software. (XLSX $104 \mathrm{~kb}$ )
Additional file 3: Significant biological functions associated with the differentiation phase of adipogenesis determined by IPA software. (XLSX $14 \mathrm{~kb}$ )

Additional file 4: List of genes from the highlighted biological functions associated with the differentiation phase of adipogenesis determined by IPA software. (XLSX $47 \mathrm{~kb})$

\section{Abbreviations}

ACSL: Long-chain acyl-CoA synthetase; C/EBP: CCAAT-enhancer binding protein; GPDH: Glycerol-3-phosphate dehydrogenase; IGFBP: Insulin-like growth factor binding protein; IPA: Ingenuity pathway analysis; MSCs: Mesenchymal stem cells; PCNA: Proliferating cell nuclear antigen; PEPCK: Phosphoenolpyruvate carboxykinase; PLIN2: Perilipin 2;

PPARY: Peroxisome proliferator activated receptor $\gamma$

\section{Acknowledgments}

We thank the personnel from the animal facilities at the Faculty of Biology for the maintenance of the trout.

\section{Funding}

This work has been funded by the Ministerio de Economía y Competitividad «MINECO» (AGL2011-24961, AGL2014-57974-R), the Generalitat de Catalunya (2014SGR-01371) and the European Union (LIFECYCLE-FP7 222719). The different funding bodies had no role in study design, collection, analysis and interpretation of data or writing of the manuscript.

\section{Availability of data and materials}

Microarray data sets have been submitted to the GEO-NCBI (accession number GSE90058).

\section{Authors' contributions}

The experiment was designed by IN, EC, JG, MB, PYR, JCG and CW. MB did the cell cultures, RNA extraction, Western blot analysis, analyzed the data and wrote the manuscript. JM, ALC, VL and CR performed microarray experiments, analyzed the data and did qPCR analysis. IN, EC, JG, PYR, JCG and CW helped draft the manuscript. All authors have read and approved the manuscript.

\section{Competing interests}

The authors declare that they have no competing interests.

Consent for publication

Non applicable.

\section{Ethics approval}

All animal handling procedures were specifically approved by the Institutional Animal Care and Use Committee of the University of Barcelona (Comitè Ėtic d'Experimentació Animal; permits reference numbers CEEA 237/12 and DAAM 6755) following the regulations and procedures established by the EU, and by the Spanish and Catalan governments.

\section{Publisher's Note}

Springer Nature remains neutral with regard to jurisdictional claims in published maps and institutional affiliations.

\section{Author details}

'Department of Cell Biology, Physiology and Immunology, Faculty of Biology, University of Barcelona, Av. Diagonal 643, 08028 Barcelona, Spain. ${ }^{2}$ INRA, UR1037 Laboratory of Fish Physiology and Genomics, Campus de Beaulieu, Rennes F-35042, France. ${ }^{3}$ Present address: Nofima (Norwegian Institute of Food, Fisheries, and Aquaculture Research), P.O. Box 210N-1432 Ås, Norway.

Received: 28 October 2016 Accepted: 26 April 2017

Published online: 04 May 2017

\section{References}

1. Weil C, Lefèvre F, Bugeon J. Characteristics and metabolism of different adipose tissues in fish. Rev Fish Biol Fisheries. 2013;23(2):157-73.

2. Rajan S, Gupta A, Beg M, Shankar K, Srivastava A, Varshney S, Kumar D, Gaikwad AN. Adipocyte transdifferentiation and its molecular targets. Differentiation. 2014;87(5):183-92. 
3. Alemany M. Relationship between energy dense diets and white adipose tissue inflammation in metabolic syndrome. Nutrition research (New York, NY). 2013;33(1):1-11.

4. Rosen ED, MacDougald OA. Adipocyte differentiation from the inside out Nat Rev Mol Cell Biol. 2006;7(12):885-96.

5. Bouraoui L, Gutierrez J, Navarro I. Regulation of proliferation and differentiation of adipocyte precursor cells in rainbow trout (Oncorhynchus mykiss). J Endocrinol. 2008;198(3):459-69.

6. Salmeron C, Acerete L, Gutierrez J, Navarro I, Capilla E. Characterization and endocrine regulation of proliferation and differentiation of primary cultured preadipocytes from gilthead sea bream (Sparus aurata). Domest Anim Endocrinol. 2013;45(1):1-10.

7. Burton GR, Nagarajan R, Peterson CA, McGehee Jr RE. Microarray analysis of differentiation-specific gene expression during 3 T3-L1 adipogenesis. Gene. 2004:329:167-85.

8. Burton GR, Guan Y, Nagarajan R, McGehee Jr RE. Microarray analysis of gene expression during early adipocyte differentiation. Gene. 2002;293(1-2):21-31.

9. Soukas A, Socci ND, Saatkamp BD, Novelli S, Friedman JM. Distinct transcriptional profiles of adipogenesis in vivo and in vitro. J Biol Chem. 2001;276(36):34167-74.

10. Guo X, Liao K. Analysis of gene expression profile during 3 T3-L1 preadipocyte differentiation. Gene. 2000;251(1):45-53.

11. Vegusdal A, Sundvold $H, G$ joen $T$, Ruyter B. An in vitro method for studying the proliferation and differentiation of Atlantic salmon preadipocytes. Lipids. 2003;38(3):289-96

12. Oku H, Umino T. Molecular characterization of peroxisome proliferatoractivated receptors (PPARs) and their gene expression in the differentiating adipocytes of red sea bream Pagrus major. Comp Biochem Physiol B Biochem Mol Biol. 2008;151(3):268-77.

13. Oku H, Tokuda M, Okumura T, Umino T. Effects of insulin, triiodothyronine and fat soluble vitamins on adipocyte differentiation and LPL gene expression in the stromal-vascular cells of red sea bream, Pagrus major. Comp Biochem Physiol B Biochem Mol Biol. 2006;144(3):326-33.

14. Todorčević M, Škugor S, Krasnov A, Ruyter B. Gene expression profiles in Atlantic salmon adipose-derived stromo-vascular fraction during differentiation into adipocytes. BMC Genomics. 2010;11:39.

15. Ali AT, Hochfeld WE, Myburgh R, Pepper MS. Adipocyte and adipogenesis. Eur J Cell Biol. 2013;92(6-7):229-36.

16. Birsoy K, Festuccia WT, Laplante M. A comparative perspective on lipid storage in animals. J Cell Sci. 2013;126(7):1541-52.

17. Cruz-Garcia L, Saera-Vila A, Navarro I, Calduch-Giner J, Perez-Sanchez J. Targets for TNFalpha-induced lipolysis in gilthead sea bream (Sparus aurata L.) adipocytes isolated from lean and fat juvenile fish. J Exp Biol. 2009;212(Pt 14):2254-60.

18. Albalat A, Liarte C, MacKenzie S, Tort L, Planas JV, Navarro I. Control of adipose tissue lipid metabolism by tumor necrosis factor-alpha in rainbow trout (Oncorhynchus mykiss). J Endocrinol. 2005;184(3):527-34.

19. Tilg $H$, Moschen AR. Adipocytokines: mediators linking adipose tissue, inflammation and immunity. Nat Rev Immunol. 2006;6(10):772-83.

20. Copeland DL, Duff RJ, Liu Q, Prokop J, Londraville RL. Leptin in teleost fishes: an argument for comparative study. Front Physiol. 2011;2:26.

21. Sanchez-Gurmaches J, Cruz-Garcia L, Gutierrez J, Navarro I. Adiponectin effects and gene expression in rainbow trout: an in vivo and in vitro approach. J Exp Biol. 2012;215(Pt 8):1373-83.

22. Kondo H, Suda S, Kawana Y, Hirono I, Nagasaka R, Kaneko G, Ushio H, Watabe $\mathrm{S}$. Effects of feed restriction on the expression profiles of the glucose and fatty acid metabolism-related genes in rainbow trout Oncorhynchus mykiss muscle. Fish Sci. 2012;78(6):1205-11.

23. Kondo H, Suga R, Suda S, Nozaki R, Hirono I, Nagasaka R, Kaneko G, Ushio H, Watabe S. EST analysis on adipose tissue of rainbow trout Oncorhynchus mykiss and tissue distribution of adiponectin. Gene. 2011;485(1):40-5.

24. Bouraoui L, Capilla E, Gutierrez J, Navarro I. Insulin and insulin-like growth factor I signaling pathways in rainbow trout (Oncorhynchus mykiss) during adipogenesis and their implication in glucose uptake. Am J Physiol Regul Integr Comp Physiol. 2010;299(1):R33-41.

25. Weil C, Lebret V, Gabillard JC. The IGF/IGFBP system in rainbow trout (Oncorhynchus mykiss) adipose tissue: expression related to regional localization and cell type. Fish Physiol Biochem. 2011;37(4):843-52.

26. Polakof S, Skiba-Cassy S, Kaushik S, Seiliez I, Soengas JL, Panserat S. Glucose and lipid metabolism in the pancreas of rainbow trout is regulated at the molecular level by nutritional status and carbohydrate intake. Journal of comparative physiology B, Biochemical, systemic, and environmental physiology. 2012;182(4):507-16
27. Rescan PY, Montfort J, Fautrel A, Rallière C, Lebret V. Gene expression profiling of the hyperplastic growth zones of the late trout embryo myotome using laser capture microdissection and microarray analysis. BMC Genomics. 2013;14:173.

28. Eisen MB, Spellman PT, Brown PO, Botstein D. Cluster analysis and display of genome-wide expression patterns. Proc Natl Acad Sci U S A. 1998;95(25):14863-8.

29. Bou M, Todorcevic M, Rodríguez J, Capilla E, Gutiérrez J, Navarro I. Interplay of adiponectin, TNFalpha and insulin on gene expression, glucose uptake and PPARgamma, AKT and TOR pathways in rainbow trout cultured adipocytes. Gen Comp Endocrinol. 2014;205:218-25.

30. Azizi S, Nematollahi MA, Amiri BM, Vélez EJ, Salmerón C, Chan SJ, Navarro I, Capilla E, Gutiérrez J. IGF-I and IGF-II effects on local IGF system and signaling pathways in gilthead sea bream (Sparus aurata) cultured myocytes. Gen Comp Endocrinol. 2015;232:7-16.

31. Aminova LR, Wilson BA. Calcineurin-independent inhibition of 3 T3-L1 adipogenesis by Pasteurella multocida toxin: suppression of Notch1, stabilization of beta-catenin and pre-adipocyte factor 1. Cell Microbiol. 2007;9(10):2485-96.

32. Carnevalli LS, Masuda K, Frigerio F, Le Bacquer O, Um SH, Gandin V, Topisirovic I, Sonenberg N, Thomas G, Kozma SC. S6K1 Plays a Critical Role in Early Adipocyte Differentiation. Dev Cell. 2010;18(5):763-74.

33. De Sousa M, Porras DP, Perry CG, Seale P, Scime A. p107 is a crucial regulator for determining the adipocyte lineage fate choices of stem cells. Stem cells (Dayton, Ohio). 2014;32(5):1323-36.

34. Ng F, Boucher S, Koh S, Sastry KSR, Chase L, Lakshmipathy U, Choong C, Yang Z, Vemuri MC, Rao MS, et al. PDGF, TGF- $\beta$, and FGF signaling is important for differentiation and growth of mesenchymal stem cells (MSCS): transcriptional profiling can identify markers and signaling pathways important in differentiation of MSCs into adipogenic, chondrogenic, and osteogenic lineages. Blood. 2008;112(2): 295-307.

35. Malemud CJ. Matrix metalloproteinases (MMPs) in health and disease: an overview. Frontiers in bioscience : a journal and virtual library. 2006;11:1696-701.

36. Bouloumié A, Sengenès C, Portolan G, Galitzky J, Lafontan M. Adipocyte produces matrix metalloproteinases 2 and 9: involvement in adipose differentiation. Diabetes. 2001;50(9):2080-6.

37. Chun TH, Hotary KB, Sabeh F, Saltiel AR, Allen ED, Weiss SJ. A pericellular collagenase directs the 3-dimensional development of white adipose tissue. Cell. 2006;125(3):577-91.

38. Cristancho AG, Lazar MA. Forming functional fat: a growing understanding of adipocyte differentiation. Nat Rev Mol Cell Biol. 2011;12(11):722-34.

39. McBeath R, Pirone DM, Nelson CM, Bhadriraju K, Chen CS. Cell shape, cytoskeletal tension, and RhoA regulate stem cell lineage commitment. Dev Cell. 2004;6(4):483-95.

40. Subramani S, Malhotra V. Non-autophagic roles of autophagy-related proteins. EMBO Rep. 2013;14(2):143-51.

41. Zhang $Y$, Zeng $X$, Jin S. Autophagy in adipose tissue biology. Pharmacol Res. 2012;66(6):505-12.

42. Singh $R$, Xiang Y, Wang Y, Baikati K, Cuervo AM, Luu YK, Tang Y, Pessin JE, Schwartz GJ, Czaja MJ. Autophagy regulates adipose mass and differentiation in mice. J Clin Invest. 2009;119(11):3329-39.

43. Baerga R, Zhang Y, Chen PH, Goldman S, Jin S. Targeted deletion of autophagy-related 5 (atg5) impairs adipogenesis in a cellular model and in mice. Autophagy. 2009;5(8):1118-30.

44. Kon M, Cuervo AM. Chaperone-mediated autophagy in health and disease. FEBS Lett. 2010;584(7):1399-404.

45. Lijnen HR. Angiogenesis and obesity. Cardiovasc Res. 2008;78(2):286-93.

46. Lafontan M. Adipose tissue and adipocyte dysregulation. Diabetes Metab. 2014:40(1):16-28.

47. Cai L, Johnstone BH, Cook TG, Liang Z, Traktuev D, Cornetta K, Ingram DA Rosen ED, March KL. Suppression of hepatocyte growth factor production impairs the ability of adipose-derived stem cells to promote ischemic tissue revascularization. Stem cells (Dayton, Ohio). 2007;25(12):3234-43.

48. Sarjeant K, Stephens JM. Adipogenesis. Cold Spring Harb Perspect Biol. 2012;4(9):a008417.

49. Andreucci JJ, Grant D, Cox DM, Tomc LK, Prywes R, Goldhamer DJ, Rodrigues N, Bedard PA, McDermott JC. Composition and function of AP-1 transcription complexes during muscle cell differentiation. J Biol Chem. 2002;277(19):16426-32

50. Wagner EF. AP-1-Introductory remarks. Oncogene. 2001;20(19):2334-5.

51. Distel RJ, Ro HS, Rosen BS, Groves DL, Spiegelman BM. Nucleoprotein complexes that regulate gene expression in adipocyte differentiation: direct participation of c-fos. Cell. 1987;49(6):835-44. 
52. Xiao H, LeBlanc SE, Wu Q, Konda S, Salma N, Marfella CGA, Ohkawa Y, Imbalzano AN. Chromatin accessibility and transcription factor binding at the PPARY2 promoter during adipogenesis is protein kinase A-dependent. J Cell Physiol. 2011;226(1):86-93.

53. Knebel B, Kotzka J, Lehr S, Hartwig S, Avci H, Jacob S, Nitzgen U, Schiller M, Marz W, Hoffmann MM, et al. A mutation in the c-fos gene associated with congenital generalized lipodystrophy. Orphanet J Rare Dis. 2013;8:119.

54. Wrann CD, Eguchi J, Bozec A, Xu Z, Mikkelsen T, Gimble J, Nave H, Wagner EF, Ong SE, Rosen ED. FOSL2 promotes leptin gene expression in human and mouse adipocytes. J Clin Invest. 2012;122(3):1010-21.

55. Luther J, Ubieta K, Hannemann N, Jimenez M, Garcia M, Zech C, Schett G, Wagner EF, Bozec A. Fra-2/AP-1 controls adipocyte differentiation and survival by regulating PPARgamma and hypoxia. Cell Death Differ. 2014; 21(4):655-64.

56. Kveiborg M, Sabatakos G, Chiusaroli R, Wu M, Philbrick WM, Horne WC, Baron R. $\triangle$ FosB induces osteosclerosis and decreases adipogenesis by two independent cell-autonomous mechanisms. Mol Cell Biol. 2004;24(7):2820-30.

57. Jang MK, Kim CH, Seong JK, Jung MH. ATF3 inhibits adipocyte differentiation of 3 T3-L1 cells. Biochem Biophys Res Commun. 2012;421(1):38-43.

58. Farmer SR. Transcriptional control of adipocyte formation. Cell Metab. 2006; 4(4):263-73.

59. Fajas L, Landsberg RL, Huss-Garcia Y, Sardet C, Lees JA, Auwerx J. E2Fs regulate adipocyte differentiation. Dev Cell. 2002;3(1):39-49.

60. Meruvu S, Hugendubler L, Mueller E. Regulation of adipocyte differentiation by the zinc finger protein ZNF638. J Biol Chem. 2011;286(30):26516-23.

61. Chen Z, Torrens JI, Anand A, Spiegelman BM, Friedman JM. Krox20 stimulates adipogenesis via C/EBPbeta-dependent and -independent mechanisms. Cell Metab. 2005;1(2):93-106.

62. Cao Z, Umek RM, McKnight SL. Regulated expression of three C/EBP isoforms during adipose conversion of 3 T3-L1 cells. Genes Dev. 1991;5(9): 1538-52.

63. Lowe CE, O'Rahilly S, Rochford JJ. Adipogenesis at a glance. J Cell Sci. 2011; 124(Pt 16):2681-6.

64. Birsoy K, Chen Z, Friedman J. Transcriptional regulation of adipogenesis by KLF4. Cell Metab. 2008;7(4):339-47.

65. Gray S, Feinberg MW, Hull S, Kuo CT, Watanabe M, Sen-Banerjee S, DePina A, Haspel R, Jain MK. The Krüppel-like factor KLF15 regulates the insulinsensitive glucose transporter GLUT4. J Biol Chem. 2002;277(37):34322-8.

66. Marín-Juez R, Diaz M, Morata J, Planas JV. Mechanisms Regulating GLUT4 Transcription in Skeletal Muscle Cells Are Highly Conserved across Vertebrates. PLoS One. 2013;8(11), e80628.

67. Oates AC, Pratt SJ, Vail B, Yan Y, Ho RK, Johnson SL, Postlethwait JH, Zon LI. The zebrafish klf gene family. Blood. 2001;98(6):1792-801.

68. Xue Y, Gao S, Liu F. Genome-wide analysis of the zebrafish Klf family identifies two genes important for erythroid maturation. Dev Biol. 2015;403(2):115-27.

69. Charlier C, Montfort J, Chabrol O, Brisard D, Nguyen T, Le Cam A, RichardParpaillon L, Moreews F, Pontarotti P, Uzbekova S, et al. Oocyte-somatic cells interactions, lessons from evolution. BMC Genomics. 2012;13:560.

70. Tong Q, Dalgin G, Xu H, Ting CN, Leiden JM, Hotamisligil GS. Function of GATA transcription factors in preadipocyte-adipocyte transition. Science (New York, NY). 2000;290(5489):134-8.

71. Tsuchiya M, Misaka R, Nitta K, Tsuchiya K. Transcriptional factors, Mafs and their biological roles. World J Diabetes. 2015;6(1):175-83.

72. Bernhard F, Landgraf K, Kloting N, Berthold A, Buttner P, Friebe D, Kiess W, Kovacs $\mathrm{P}$, Bluher $\mathrm{M}$, Korner A. Functional relevance of genes implicated by obesity genome-wide association study signals for human adipocyte biology. Diabetologia. 2013;56(2):311-22.

73. Seifert A, Werheid DF, Knapp SM, Tobiasch E. Role of Hox genes in stem cell differentiation. World Journal of Stem Cells. 2015;7(3):583-95.

74. Cowherd RM, Lyle RE, Miller CP, McGehee Jr RE. Developmental profile of homeobox gene expression during 3 T3-L1 adipogenesis. Biochem Biophys Res Commun. 1997:237(2):470-5.

75. Cantile M, Procino A, D'Armiento M, Cindolo L, Cillo C. HOX gene network is involved in the transcriptional regulation of in vivo human adipogenesis. J Cell Physiol. 2003;194(2):225-36.

76. Karastergiou K, Fried SK, Xie H, Lee M-J, Divoux A, Rosencrantz MA, Chang RJ, Smith SR. Distinct developmental signatures of human abdominal and gluteal subcutaneous adipose tissue depots. J Clin Endocrinol Metab. 2013; 98(1):362-71.

77. Gubelmann C, Schwalie PC, Raghav SK, Röder E, Delessa T, Kiehlmann E, Waszak SM, Corsinotti A, Udin G, Holcombe W, et al. Identification of the transcription factor ZEB1 as a central component of the adipogenic gene regulatory network. Elife. 2014;3, e03346.

78. Dankel SN, Fadnes DJ, Stavrum A-K, Stansberg C, Holdhus R, Hoang T, Veum $V L$, Christensen BJ, Våge V, Sagen JV, et al. Switch from stress response to homeobox transcription factors in adipose tissue after profound fat loss. PLoS One. 2010;5(6), e11033.

79. Siersbaek R, Nielsen R, Mandrup S. Transcriptional networks and chromatin remodeling controlling adipogenesis. Trends in endocrinology and metabolism: TEM. 2012;23(2):56-64.

80. Mikkelsen TS, Xu Z, Zhang X, Wang L, Gimble JM, Lander ES, Rosen ED. Comparative epigenomic analysis of murine and human adipogenesis. Cell. 2010;143(1):156-69.

81. Musri MM, Parrizas M. Epigenetic regulation of adipogenesis. Curr Opin Clin Nutr Metab Care. 2012;15(4):342-9.

82. Takada I, Mihara M, Suzawa M, Ohtake F, Kobayashi S, Igarashi M, Youn MY, Takeyama K, Nakamura T, Mezaki Y, et al. A histone lysine methyltransferase activated by non-canonical Wnt signalling suppresses PPAR-gamma transactivation. Nat Cell Biol. 2007;9(11):1273-85

83. Wang L, Jin Q, Lee J-E, Su IH, Ge K. Histone H3K27 methyltransferase Ezh2 represses Wnt genes to facilitate adipogenesis. Proc Natl Acad Sci. 2010; 107(16):7317-22.

84. Suvasini R, Shruti B, Thota B, Shinde SV, Friedmann-Morvinski D, Nawaz Z, Prasanna KV, Thennarasu K, Hegde AS, Arivazhagan A, et al. Insulin growth factor-2 binding protein 3 (IGF2BP3) is a glioblastoma-specific marker that activates phosphatidylinositol 3-kinase/mitogen-activated protein kinase (PI3K MAPK) pathways by modulating IGF-2. J Biol Chem. 2011;286(29):25882-90.

85. Duan C, Ren H, Gao S. Insulin-like growth factors (IGFs), IGF receptors, and IGF-binding proteins: roles in skeletal muscle growth and differentiation. Gen Comp Endocrinol. 2010;167(3):344-51.

86. Firth SM, Baxter RC. Cellular actions of the insulin-like growth factor binding proteins. Endocr Rev. 2002;23(6):824-54

87. Duan C, Xu Q. Roles of insulin-like growth factor (IGF) binding proteins in regulating IGF actions. Gen Comp Endocrinol. 2005;142(1-2):44-52.

88. Baxter RC, Twigg SM. Actions of IGF binding proteins and related proteins in adipose tissue. Trends in endocrinology and metabolism: TEM. 2009; 20(10):499-505.

89. Siddle K. Signalling by insulin and IGF receptors: supporting acts and new players. J Mol Endocrinol. 2011:47(1):R1-10.

90. Dearth RK, Cui X, Kim HJ, Kuiatse I, Lawrence NA, Zhang X, Divisova J, Britton OL, Mohsin S, Allred DC, et al. Mammary tumorigenesis and metastasis caused by overexpression of insulin receptor substrate 1 (IRS-1) or IRS-2. Mol Cell Biol. 2006;26(24):9302-14.

91. DeMambro VE, Kawai M, Clemens TL, Fulzele K, Maynard JA, Marin de Evsikova C, Johnson KR, Canalis E, Beamer WG, Rosen CJ, et al. A novel spontaneous mutation of Irs 1 in mice results in hyperinsulinemia, reduced growth, low bone mass and impaired adipogenesis. J Endocrinol. 2010;204(3):241-53.

92. Aubin D, Gagnon A, Sorisky A. Phosphoinositide 3-kinase is required for human adipocyte differentiation in culture. Int J Obes (Lond). 2005;29(8):1006-9.

93. Polus A, Kiec-Wilk B, Razny U, Gielicz A, Schmitz G, Dembinska-Kiec A Influence of dietary fatty acids on differentiation of human stromal vascular fraction preadipocytes. Biochimica et Biophysica Acta (BBA) - Molecular and Cell Biology of Lipids. 2015;1851(9):1146-55.

94. Grygiel-Górniak B. Peroxisome proliferator-activated receptors and their ligands: nutritional and clinical implications - a review. Nutr J. 2014;13:17.

95. Madsen L, Petersen RK, Sorensen MB, Jorgensen C, Hallenborg P, Pridal L, Fleckner J, Amri EZ, Krieg P, Furstenberger G, et al. Adipocyte differentiation of 3 T3-L1 preadipocytes is dependent on lipoxygenase activity during the initial stages of the differentiation process. Biochem J. 2003;375(Pt 3):539-49.

96. Kuhn H, Banthiya S, van Leyen K. Mammalian lipoxygenases and their biological relevance. Biochimica et Biophysica Acta (BBA) - Molecular and Cell Biology of Lipids. 2015;1851(4):308-30.

97. Shillabeer G, Kumar V, Tibbo E, Lau DCW. Arachidonic acid metabolites of the lipoxygenase as well as the cyclooxygenase pathway may be involved in regulating preadipocyte differentiation. Metab Clin Exp. 1998;47(4):461-6.

98. Yan H, Kermouni A, Abdel-Hafez M, Lau DC. Role of cyclooxygenases COX-1 and COX-2 in modulating adipogenesis in 3 T3-L1 cells. J Lipid Res. 2003; 44(2):424-9.

99. Pastel E, Pointud JC, Loubeau G, Dani C, Slim K, Martin G, Volat F, SahutBarnola I, Val P, Martinez A, et al. Aldose reductases influence prostaglandin F2alpha levels and adipocyte differentiation in male mouse and human species. Endocrinology. 2015;156(5):1671-84. 
100. Tacconelli S, Patrignani P. Inside epoxyeicosatrienoic acids and cardiovascular disease. Front Pharmacol. 2014:5:239.

101. Zha W, Edin ML, Vendrov KC, Schuck RN, Lih FB, Jat JL, Bradbury JA, DeGraff LM, Hua K, Tomer KB, et al. Functional characterization of cytochrome P450derived epoxyeicosatrienoic acids in adipogenesis and obesity. J Lipid Res. 2014;55(10):2124-36.

102. Moreno M, Lombardi A, Silvestri E, Senese R, Cioffi F, Goglia F, Lanni A, de Lange P. PPARs: nuclear receptors controlled by, and controlling. Nutrient handling through nuclear and cytosolic signaling. PPAR Res. 2010;2010:10.

103. Lu C, Cheng SY. Thyroid hormone receptors regulate adipogenesis and carcinogenesis via crosstalk signaling with peroxisome proliferator-activated receptors. J Mol Endocrinol. 2010;44(3):143-54.

104. Hotamisligil GS, Bernlohr DA. Metabolic functions of FABPs - mechanisms and therapeutic implications. Nat Rev Endocrinol. 2015;11(10):592-605.

105. Storch J, Thumser AE. Tissue-specific functions in the fatty acid-binding protein family. J Biol Chem. 2010;285(43):32679-83.

106. Thumser AE, Moore JB, Plant NJ. Fatty acid binding proteins: tissue-specific functions in health and disease. Curr Opin Clin Nutr Metab Care. 2014;17(2):124-9.

107. Weil C, Sabin N, Bugeon J, Paboeuf G, Lefevre F. Differentially expressed proteins in rainbow trout adipocytes isolated from visceral and subcutaneous tissues. Comp Biochem Physiol Part D Genomics Proteomics. 2009;4(3):235-41.

108. Tan NS, Shaw NS, Vinckenbosch N, Liu P, Yasmin R, Desvergne B, Wahli W, Noy N. Selective cooperation between fatty acid binding proteins and peroxisome proliferator-activated receptors in regulating transcription. Mol Cell Biol. 2002;22(14):5114-27.

109. Hunt MC, Siponen MI, Alexson SEH. The emerging role of acyl-CoA thioesterases and acyltransferases in regulating peroxisomal lipid metabolism. Biochim Biophys Acta (BBA) - Mol Basis Dis. 2012;1822(9):1397-410.

110. Violante $S$, Ijlst L, te Brinke H, Koster J, Tavares de Almeida I, Wanders RJA, Ventura FV, Houten SM. Peroxisomes contribute to the acylcarnitine production when the carnitine shuttle is deficient. Biochimica et Biophysica Acta (BBA) - Molecular and Cell Biology of Lipids. 2013;1831(9):1467-74.

111. Cabrero À, Alegret M, Sánchez RM, Adzet T, Laguna JC, Vázquez M. Bezafibrate reduces mRNA levels of adipocyte markers and increases fatty acid oxidation in primary culture of adipocytes. Diabetes. 2001;50(8):1883-90.

112. Rutkowski JM, Stern JH, Scherer PE. The cell biology of fat expansion. J Cell Biol. 2015;208(5):501-12.

113. Konige $M$, Wang $H$, Sztalryd $C$. Role of adipose specific lipid droplet proteins in maintaining whole body energy homeostasis. Biochim Biophys Acta (BBA) - Mol Basis Dis. 2014;1842(3):393-401.

114. Keller P, Petrie JT, De Rose P, Gerin I, Wright WS, Chiang SH, Nielsen AR, Fischer CP, Pedersen BK, MacDougald OA. Fat-specific protein 27 regulates storage of triacylglycerol. J Biol Chem. 2008;283(21):14355-65.

115. Le Lay S, Blouin CM, Hajduch E, Dugail I. Filling up adipocytes with lipids. Lessons from caveolin-1 deficiency. Biochim Biophys Acta. 2009;1791(6):514-8.

116. Bostrom P, Andersson L, Rutberg M, Perman J, Lidberg U, Johansson BR Fernandez-Rodriguez J, Ericson J, Nilsson T, Boren J, et al. SNARE proteins mediate fusion between cytosolic lipid droplets and are implicated in insulin sensitivity. Nat Cell Biol. 2007;9(11):1286-93.

117. Love JD, Suzuki T, Robinson DB, Harris CM, Johnson JE, Mohler PJ, Jerome WG, Swift LL. Microsomal triglyceride transfer protein (MTP) associates with cytosolic lipid droplets in 3 T3-L1 adipocytes. PLoS One. 2015;10(8), e0135598.

118. Tormos KV, Anso E, Hamanaka RB, Eisenbart J, Joseph J, Kalyanaraman B, Chandel NS. Mitochondrial complex III ROS regulate adipocyte differentiation. Cell Metab. 2011;14(4):537-44.

119. Vigilanza P, Aquilano K, Baldelli S, Rotilio G, Ciriolo MR. Modulation of intracellular glutathione affects adipogenesis in 3 T3-L1 cells. J Cell Physiol. 2011;226(8):2016-24

120. Bahn YJ, Lee KP, Lee SM, Choi JY, Seo YS, Kwon KS. Nucleoredoxin promotes adipogenic differentiation through regulation of Wnt/betacatenin signaling. J Lipid Res. 2015:56(2):294-303.

\section{Submit your next manuscript to BioMed Central and we will help you at every step:}

- We accept pre-submission inquiries

- Our selector tool helps you to find the most relevant journal

- We provide round the clock customer support

- Convenient online submission

- Thorough peer review

- Inclusion in PubMed and all major indexing services

- Maximum visibility for your research

Submit your manuscript at www.biomedcentral.com/submit
) Biomed Central 